\title{
In-process Measurements for Reactive Extrusion Monitoring and Control
}

\author{
José A. Covas
}

University of Minho, Department of Polymer Engineering, Institute for Polymers and Composites/13N, Guimarães 4800-058, Portugal

\subsection{Introduction}

Reactive extrusion combines melt extrusion and chemical reactions in a single operation to polymerize monomers, modify polymers, compatibilize immiscible polymer blends, or synthesize in situ nanoparticles in a polymer matrix. Current industrial reactive extrusion operations may encompass several stages, including feeding the ingredients (either together or sequentially, as pellets, powder, flakes, or liquids), melting (at least some of them), mixing (which involves distributive and dispersive mixing with specific degrees of intensity), devolatilizing and die forming for subsequent pelletization. Chemical reactions typically start to develop from the onset of melting and, depending on the type of reaction, full chemical conversion is generally obtained somewhere along the screw axis $[1,2]$.

The use of single-screw extruders for polymerization reactions began in the 1950s, in order to avoid the use of solvents, accomplish continuous manufacture, and minimize energy consumption (e.g., by elimination of solvent heating and cooling). However, despite the gradual improvements in screw design, these machines offer limited sequential addition capabilities, which confine their applicability to relatively simple operations, such as modification of polyolefins with peroxide or silane grafting [3]. Twin-screw extruders, or combinations of various kinds of equipment, were progressively adopted to better fulfill the specificities of some processes and chemical reactions $[4,5]$. Counter-rotating intermeshing self-wiping twin-screw extruders were successfully utilized for copolymerization of styrene- $n$-butyl methacrylate, polymerization of $\varepsilon$-caprolactam, grafting of maleic anhydride (MA) on to polyethylene, polymerization of urethanes, or radical polymerization of methacrylates [6]. However, as they operate at low screw speeds (because flow in the calender gap of the intermeshing screws pulls these apart against the barrel wall causing abrasion), shear rate levels are moderate and so is dispersion efficiency. Likewise, non-intermeshing counter-rotating twin-screw extruders were applied to perform polycondensation reactions due to their excellent distributive mixing, but they have limited pressure generation 
and dispersive mixing capabilities. Co-rotating intermeshing twin-screw extruders have been widely used for reactive extrusion on account of their modular construction (enabling the geometries of both screws and barrel to create the thermomechanical environment suitable for each specific application), high yield, and independent control over output and screw speed [7].

Extruder settings include screw speed, barrel and die temperatures, feed rate (in the case of twin-screw extruders and starve-fed single-screw extruders) and vacuum pressure (if devolatilization is taking place). Regardless of the eventual complexity of the chemo-physical-rheological phenomena that develops inside the extruder, the process parameters that are conventionally monitored comprise motor torque, melt pressure, and melt temperature (the last two being often measured at the die entrance). Although variations in time of these parameters are caused by changes in the overall flow conditions (e.g., partial clogging of the filters, progressive screw wear, perturbations in feeding, surging, viscous dissipation, equipment malfunction - e.g., a heater band not working), and/or in the characteristics of the polymer system (e.g., degree of chemical conversion, molecular weight (MW) or molecular weight distribution (MWD), viscosity, composition, morphology), isolation of the cause(s) is often difficult. Material characterization for quality control is habitually done by collecting extrudate samples at regular intervals, followed by standard off-line testing (a typical test to check a controlled degradation reaction would be the melt flow rate (MFR)). In this context, Machado et al. [8] developed a sampling technique that enabled the rapid collection of material from within the extruder at several barrel locations, which was subsequently used to investigate the evolution of chemistry, morphology, and rheology along the extruder axis during reactive processing of various polymer systems [9-13]. Figure 5.1 shows a representative result: the effect of screw speed on the evolution of melt temperature along the screw axis of a co-rotating twin-screw extruder and die during compounding of polylactic acid (PLA) with a chain extender, as measured by sticking a fast response thermocouple into the fresh collected melt. Melting starts at screw turn number 9, as the material flows through a kneading block extending up to screw turn 11.

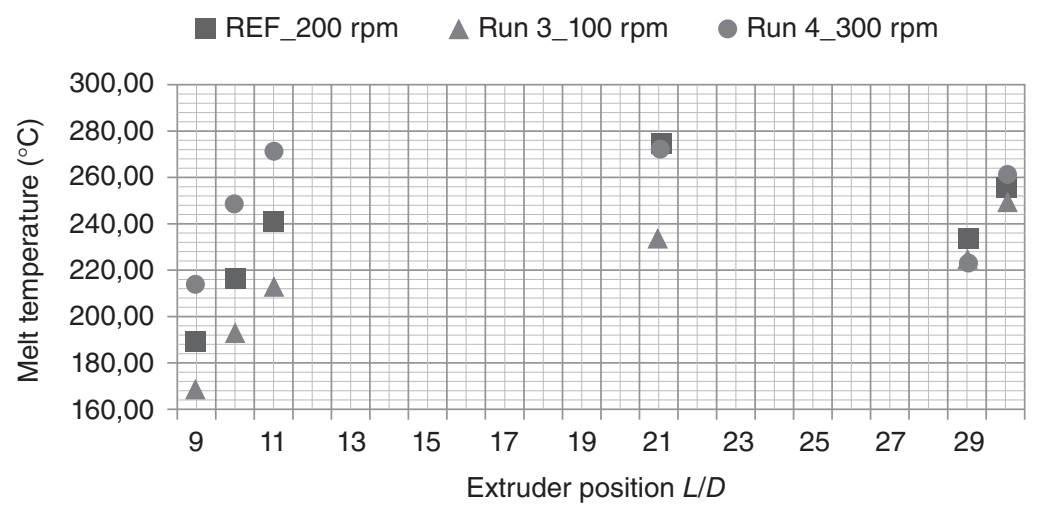

Figure 5.1 Effect of screw speed on the evolution of melt temperature along the screw axis and die of a co-rotating twin-screw extruder, upon compounding of PLA with a chain extender (unpublished data). 
Varying the screw speed between 100 and $300 \mathrm{rpm}$ generates melt temperature differences of up to $60^{\circ} \mathrm{C}$ in this region, which are attenuated downstream, as the material flows in partially filled channels separating shorter restrictive zones. Although useful - this data is not available for practical reactive extrusion operations - this approach is complicated and time consuming and may therefore bring about a delay between sample collection and test result, thus affecting its effectiveness for quality control. Moreover, in certain cases, sampling for subsequent testing may actually generate misleading data because the morphology/degree of conversion of the material may be altered during the preparation of specimens for testing (for instance, making disks for rotational rheometry). On the other hand, current process control consists in keeping the extruder settings within narrow tolerances around set values, that is, control is independent of the characteristics of the material being manufactured. If sufficiently fast and frequent data pertaining to a crucial characteristic of the material could be obtained (ideally, in real time), a different process control paradigm could be developed, whereby the extruder settings would be changed in order to keep the value of that characteristic essentially constant $[14,15]$. Thus, both efficient quality and process control in reactive extrusion require swift monitoring of material attributes relating to the plasticating sequence and to the chemical reaction.

In-process (also denoted as at-line) measurements [16], that is, measurements of material characteristics performed by devices coupled to the extruder as reactive extrusion progresses, made without disrupting the flow and by providing data in real time, are thus highly desirable. Although these goals have not been fully attained yet, it is currently possible the viscosity, the average MW and MWD, and the level of degradation of a polymer directly on the extruder, as well as to monitor the extent of a reaction, or the particle size of a suspension. This chapter discusses the challenges faced by in-process measurements for reactive extrusion and presents the approaches and techniques that seem to show more potential for widespread application. A few practical examples of their utilization are also provided.

\subsection{Requirements of In-process Monitoring of Reactive Extrusion}

In-process monitoring of reactive extrusion is advantageous for:

- assembling material data that would otherwise be lengthy or problematic to acquire off-line; additionally, for collecting large amounts of data, or obtaining data at short time intervals, as the burden of manual sample collection and taking samples to the laboratory is circumvented;

- implementing a quality control scheme that is capable of assessing process stability, capable of detecting material batch-to-batch variations and uncovering process/material attribute trends that may ultimately lead to product non-conformities, and capable of achieving a short time lag between sample collection and test result;

- assessing the compatibility between the kinetics of the chemical processes and the operating conditions and residence times in the extruder; 
- obtaining a better scientific understanding of specific reactive extrusion schemes, namely in terms of establishing correlations between chemical conversion, operating conditions, and material properties;

- gathering experimental data to be used for the evaluation of process modeling routines;

- supporting quicker material and/or process development, optimization, or scale-up (e.g., determining the best operating window, fine-tuning a formulation);

- assisting (automatic) process control based on a specific material attribute; for instance, since the rheological response of a polymer changes with the degree of polymerization, MW, and MWD, in-process rheometry was initially proposed for the closed loop control of the peroxide-initiated degradation of polypropylene (PP) [15].

In-process measurements to monitor polymer compounding and reactive extrusion are mostly performed using optical spectroscopy (ultraviolet-visible (UV-Vis), infrared (IR), Fourier transform infrared (FTIR), near-infrared (NIR), and Raman) as it provides molecular information or data on chemical composition and rheometry, which is sensitive to the structure and morphological features at various scales. The application of these techniques is discussed further (see a few case studies in [17]). Nonetheless, many other methods, such as other spectroscopy techniques (e.g., fluorescence), light scattering, polarimetry, turbidity, ultrasonic attenuation, and electric conductivity could also be of practical interest for quality control purposes. It is worth mentioning that, in the case of polymer blending and nanoparticle synthesis, reactive extrusion aims at creating stable and fine entities with sizes in the nanometer scale, which may defy the resolution provided by some techniques. Fluorescence spectroscopy is primarily employed to monitor residence times via the addition of fluorescent tracers in the melt [17-19], but could also be used to monitor additive concentrations. Time is a key parameter in chemical reactions and the residence time distribution (RTD) offers an estimation of the mixing history of the material. Figure 5.2 illustrates the set-up developed by Carneiro et al. [19] to measure the average residence time and the RTD at various locations along the barrel of a co-rotating twin-screw extruder. In these machines, changes in screw speed should not disturb the average residence time. However, as shown in Figure 5.3 for the same reactive extrusion operation considered in Figure 5.1, the boundaries of RTD vary with screw speed, that is, the minimum local residence time decreases with increasing screw speed (Figure 5.3a), the effect being smaller for the maximum residence time. In other words, screw speed influences the breadth of RTD and its progress along the extruder. Light scattering can estimate the size and shape of suspended particles or droplets (see [20] and references there in). It was used together with rheology to study start-up flows in a rheometer and demonstrate that the characteristic overshoot of the first normal stress difference $\left(N_{1}\right)$ of uncompatibilized and compatibilized blends is similar, but shifted to shorter times for the latter, thus indicating a faster breakup process [21]. However, the technique has been rarely used in extrusion [22-25]. Teixeira et al. [20] showed that while polarized optical microscopy 


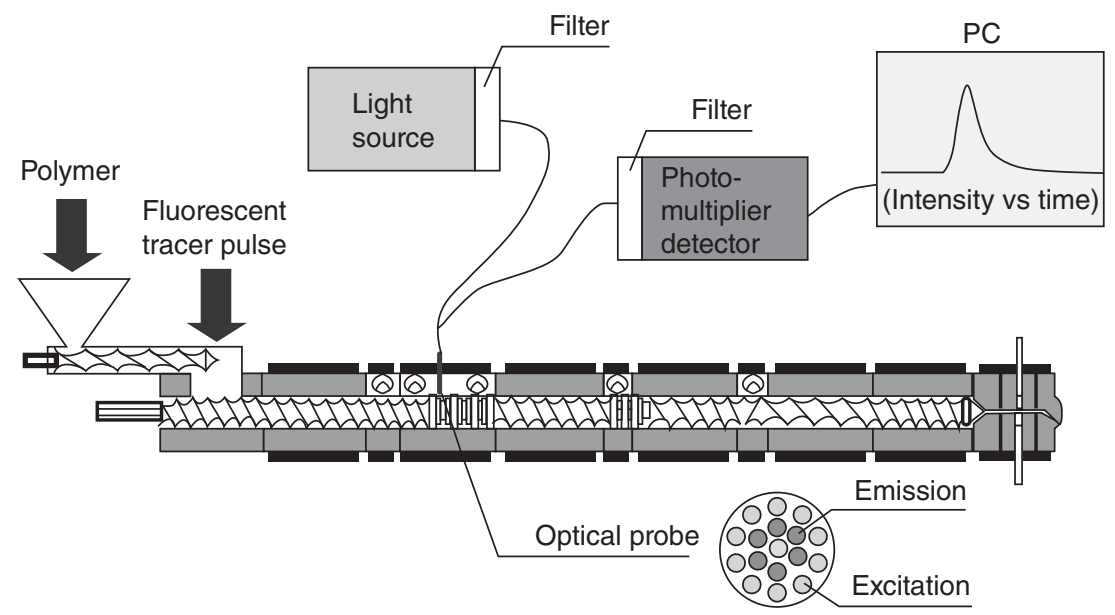

Figure 5.2 Set-up for in-process measurement of the average residence time and residence time distribution at a specific location of the extruder. The measuring probe sits in a modified barrel segment. It contacts the melt stream on one end and contains a bifurcated optical fiber bundle that transfers the light emitted by a mercury lamp source and modulated by an optical chopper, while simultaneously carrying the light emitted by the fluorescent tracer to a photodetector that converts it into a voltage signal (for details and results see [19]). (Carneiro et al. 2004 19]. Reproduced with permission of Elsevier.)

(POM) becomes ineffective below $1 \mu \mathrm{m}$, small-angle light scattering (SALS) allows access to the sub-micron scale, but only for very low-volume fractions before multiple scattering sets in (also, the refractive index of the blend components should not be very different). The limit concentration was found to decrease with the particle size of the dispersed phase. These results were in agreement with earlier observations for comparable non-reactive and reactive systems [24]. Turbidity measurements were used to estimate the dispersion level of fillers during the preparation of nanocomposites [26], or the concentration, particle size, and shape of the dispersed phase in immiscible polymer blends [27]. Again, limitations in the estimation of particle size and concentration may limit its application in reactive extrusion. Polarimetry can measure, in real time, polymer flow birefringence during extrusion. In turn, since at constant operating conditions birefringence increases with MW [28], the technique has the potential to monitor reactive extrusion. Reports are abundant on the use of ultrasound methods (vibrations with a frequency typically above $20 \mathrm{kHz}$ ) to monitor changes in polymerization, MW, density, viscosity, melt temperature, orientation and relaxation, blend composition, blend morphology, filler concentration, dispersion of solid additives, RTD, melting evolution, and so on. Application in reactive extrusion is much less frequent: Kiehl et al. [29] monitored the bulk polymerization of methyl methacrylate. The use of currently available commercial sensors for long-run operations is generally limited to $150^{\circ} \mathrm{C}$ and 30 bar. Thus, through-the-wall (i.e., via a buffer) measurements are generally the available option for melts, which makes the set-up more complicated and requires substantial construction accuracy in addition to the need to perform correction calculations to the results. 

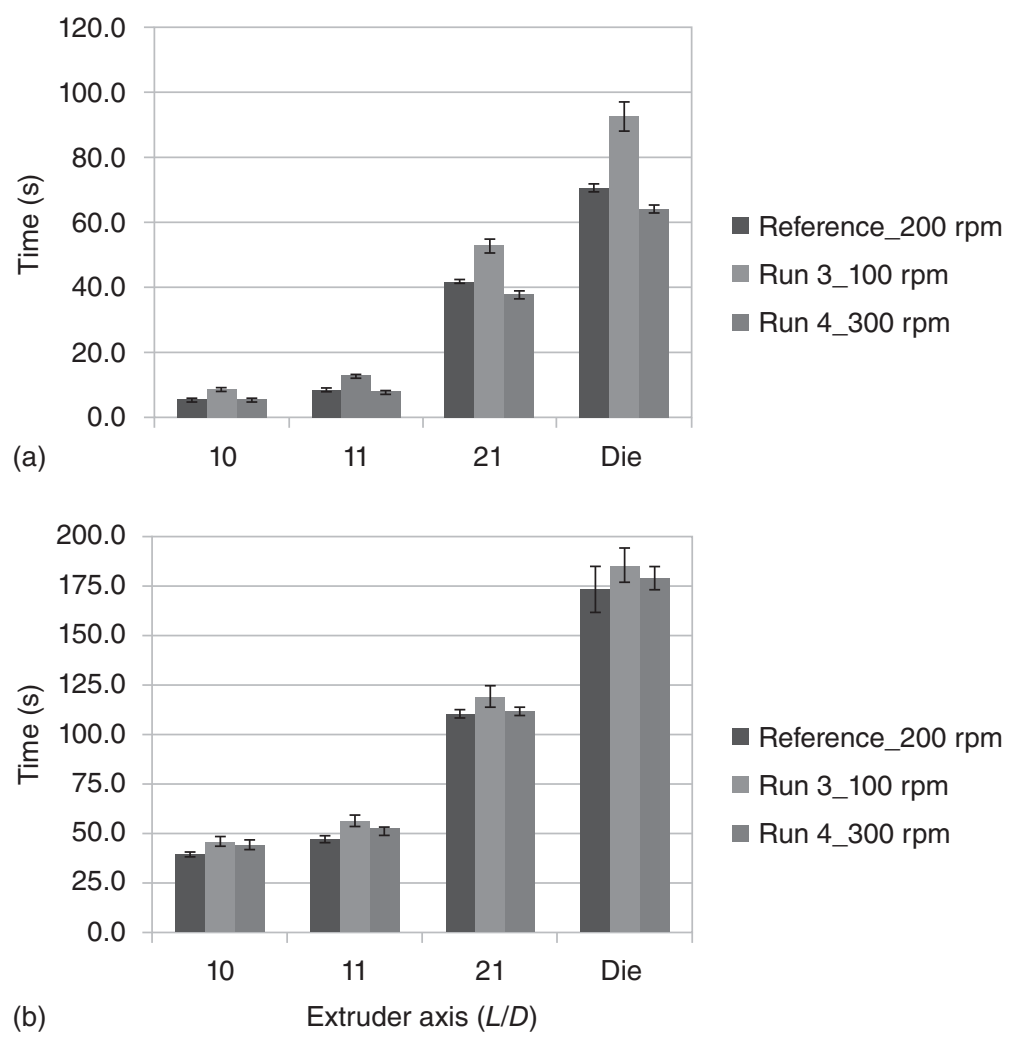

Figure 5.3 Effect of screw speed on the evolution of the minimum (a) and maximum (b) residence time along the screw axis and die of a co-rotating twin-screw extruder, upon compounding of PLA with a chain extender (unpublished data).

Therefore, despite the potential of the technique, its widespread use still requires higher robustness, accuracy, and user friendliness [30]. Finally, Perusich and McBrearty [31] used dielectric spectroscopy to monitor polymer/co-monomer composition variations during extrusion, while van Boersma and Turnhout [32] followed the morphology of a thermotropic liquid crystalline polymer (LCP)/PP blend. The technique is of recognizable relevance to monitor the manufacture of electrically conductive nanocomposites. Excellent reviews on monitoring extrusion and compounding are available, specifically focusing on rheometry [33], spectroscopic and scattering techniques [23], and pharmaceutical manufacturing [34]. In their review of the fundamental aspects of reactive processing of thermoplastics, Cassagnau et al. [35] also covered in-process monitoring.

Regardless of the technique employed, while conventional testing of a sample collected from the process performed in the laboratory is denoted as off-line, it is important to distinguish between in-process measurements made in-line and on-line. The former acquire data directly from the main melt stream (typically between extruder and die, or at die), for example, by using flush mounted sensors or a special measuring section. A representative example of the latter is the "partial Couette" flow rheometer developed by Dealy and coworkers [36], 
where a rotating drum positioned in the flow channel forms a shearing zone with the channel wall. To perform on-line measurements, a polymer melt stream or sample is detoured from the main flow; after testing, the material is either lost or rejoins the main process channel. Each of these two operational modes has both advantages and limitations [16, 23, 37]. Since in-line measurements are made directly in the flow channel, very short time delays exist between sampling and testing and no sampled material is wasted. In addition, in principle the results represent the bulk, because a significant portion of the material is tested. A notable exception is the optical technique using reflectance mode, where the depth of the signal penetration may be rather low. Conversely, trials are necessarily performed at the local processing temperature, which is most probably different from the set value due to viscous dissipation, and is hence unknown and not easy to determine. In the case of in-line rheological measurements, this fact hinders the comparison of sets of data obtained from experiments with either different material recipes or operating conditions. Furthermore, being dictated by the process flow rate, the shear rate cannot be set independently. Thus, either a single shear rate is probed or, for those solutions where the geometry of the measuring channel or the velocity of a moving wall can be adjusted, a narrow range of shear rates are scanned. Slit dies with flush mounted sensors (sometimes combining different types of techniques [23]) are often coupled to extruders, whose operating conditions are then tuned to access wider shear rate and temperature ranges. This type of in-line assembly is generally not applicable to industrial scale production, but is useful for the purpose of research and development.

Diverting a sample or a stream of material from the main flow channel in order to perform an on-line measurement inherently increases the time lag between sampling and measurement. Monitoring very fast reactions may even be at risk, as chemical conversion may proceed during sampling. On the positive side, testing away from the main flow channel may provide the opportunity to set autonomously the testing geometry, the test temperature, and/or the rate of deformation. Maintenance and cleaning operations and adjustments in the sensor or in the testing geometry while extrusion proceeds become easier. Still, if the test temperature is required to be considerably different from that of the material at the sampling point, thermal equilibration may extend significantly due to the low thermal conductivity of polymers, which in turn may induce alterations in the characteristics of the material (owing to further chemical conversion, polymer degradation, or coalescence of the dispersed phase) [38, 39]. Figure 5.4 illustrates this point by showing the required equilibration times prior to on-line capillary rheometry testing at $200^{\circ} \mathrm{C}$, for material collected at various extruder barrel locations. Upon sampling, the quiescent melt must wait between 10 and $60 \mathrm{~s}$ in the reservoir of the rheometer, prior to testing. Producing a melt stream bypass or returning the diverted material after the test, may not only affect the characteristics of the material but also perturb the main flow. Sampling is often made at, or close to, the main flow channel wall, and thus might not truly represent the bulk. As will be seen further, in the case of on-line rheometry, although gear pumps can control the sampling rate, the deformation rate, and the return flow accurately, they add strain and temperature to the sample. Dealy and Rey [40] showed the importance of Taylor diffusion, that is, of the axial 

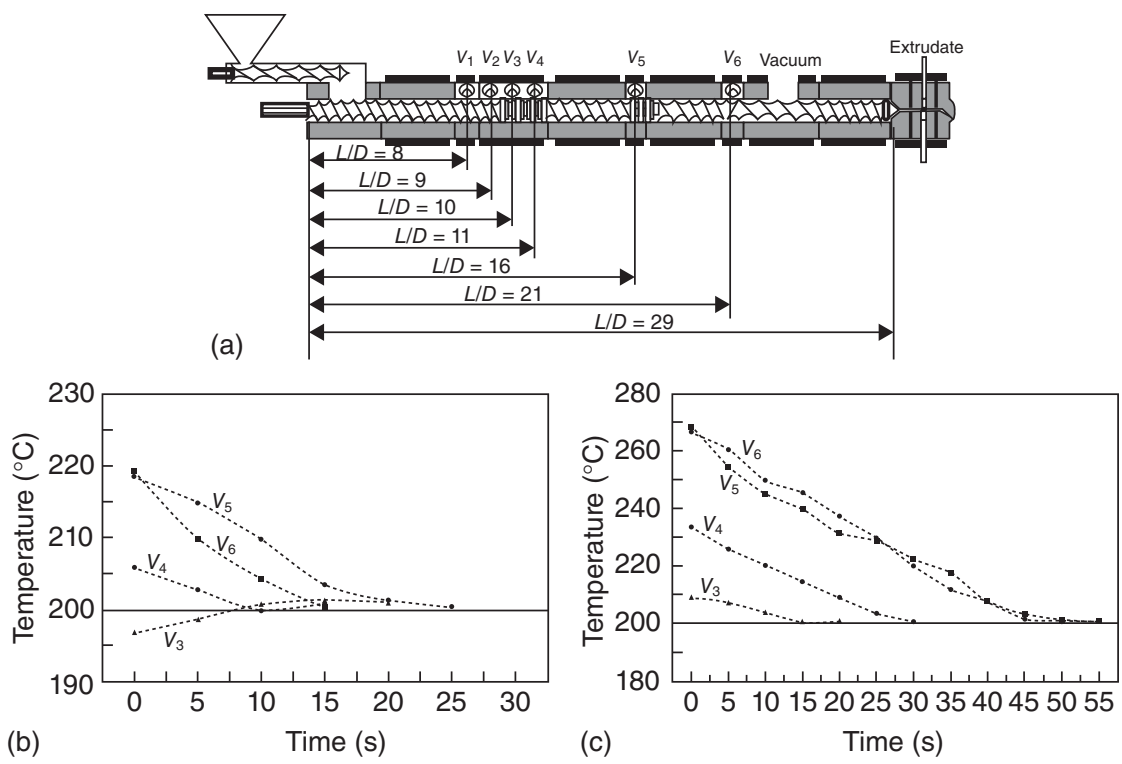

Figure 5.4 Temperature change of melt samples collected from various locations along the extruder axis $\left(v_{3}\right.$ to $\left.v_{6}\right)$ and deposited in the reservoir of an on-line rheometer set to $200^{\circ} \mathrm{C}$ prior to testing. (a) extruder set-up and locations for melt sampling/measurements; (b) results for PP with extruder barrel set to $210^{\circ} \mathrm{C}$; (c) results for HDPE with extruder barrel set to $230^{\circ} \mathrm{C}[39]$.

spreading out of the flow front due to the non-uniform velocity profile, on the dynamic response of these devices.

In-process measurements of several material characteristics (e.g., density, color, particle size, conductivity, chemical composition) or process variables (melt temperature, pressure, residence time) involve a passive interaction between sensor and sample [23, 34]. Others, such as the rheological measurement, require that the material is subjected to a controlled deformation or deformation rate, and the resulting force or change in a specific characteristic (e.g., molecular orientation, deformation of suspended droplets) is monitored [37, 41]. Given the aforementioned, designing equipment for in-process monitoring of reactive extrusion poses a number of challenges:

- The device should be able to accurately measure the relevant material response(s); data should be acquired at high rate and the test should be as rapid as possible to minimize the interval between sampling and obtaining results; output data should include both the values of the relevant material functions as well as their variation with processing time.

- The sample to be tested should be representative of the material being processed: (i) sampling and eventual thermal equilibration time for on-line measurements should not be destructive, that is should not affect the characteristics of the material, particularly its morphology; (ii) in the case of optical and vibrational measurements, sufficient path length must be ensured (this is particularly important for strong absorbing media); (iii) each measurement should be made on a fresh sample; and (iv) samples should be renewed rapidly. 
- Sampling and testing should not interfere with extrusion (e.g., causing secondary flows or stagnation zones) and, concomitantly, the main flow should not interfere with the measurement $[36,42]$.

- Probes should be able to withstand high pressures (up to $200 \mathrm{MPa}$ ) and temperatures (typically up to $350^{\circ} \mathrm{C}$, although more than $400^{\circ} \mathrm{C}$ is necessary for a few high-melting temperature polymers) and be corrosion- and abrasion-resistant.

- Probes should be easily and quickly fixed to the processing equipment. Ideally, the measuring tip of testing probes should have a geometry identical to that of conventional strain-gage melt pressure transducers of the diaphragm-type, so that they can be mounted on existing extruder barrel ports. In the case of on-line testing, melt detouring could be made through these ports.

- In-process measurements made at the die, or between screw tip and die, aim at monitoring the outcome of the reactive process, that is, to determine the degree of conversion and/or the final characteristics of the product as well as variations during production. Most in-process testing is performed in this way. Particularly during process development stages, it is advantageous to uncover the effects of type of formulation components, composition, screw design, feeding sequence, and operating conditions on the flow and reaction kinetics - and how these affect the characteristics and performance of the resulting material. Thus, measurements along the extruder axis are also important. Either ports for measurement melt pressure transducers are available, or modified barrel segments are used (examples of the latter include SALS [24], NIR spectroscopy [43], and rheometry [38, 39]).

- The data collected should be reliable and not be influenced by the mechanical vibrations of the extruder or by other interferences that arise in a typical production environment. A simple transfer of laboratory instrumentation to the process may be inadequate, as changes in construction, data acquisition time, and ensuring sufficient signal-to-noise ratio and resolution are usually necessary [23].

- The apparatus should be sufficiently compact so that it does not perturb normal operation of the compounding line, mechanically robust (this is especially relevant when using optical fibers), and guarantee proper melt sealing when applicable; user friendliness and a high level of automation are also desired.

- In-process rheological or rheo-optical testing poses additional challenges. Measurements should be performed in viscometric flows and under well-controlled conditions, in the widest possible range of deformation rates (most practical polymer melt extrusion involves shear rates between 10 and $1000 \mathrm{~s}^{-1}$ ) and temperatures (the availability of isothermal rheological functions within a span of $30^{\circ} \mathrm{C}$ is highly desirable).

The choice of the in-process techniques and of the measurement methods depends on the purpose of the application as well as on the geometry of the probes and the fixing possibilities provided by the construction of the processing equipment. The spectra collected by optical spectroscopy may be correlated with composition as well as with the structural and morphological features. In the case of rheology, on-line capillary rheometers yield a viscosity flow curve (or the much simpler MFR), which is appropriate to characterize 
polymerization, chain extension, and controlled degradation reactions. Small amplitude oscillatory shear (SAOS) tests are generally considered adequate to analyze in situ compatibilized polymer blends, as eventual changes in the material during testing are minimized. Extensional viscosity is quite sensitive to changes in interfacial tension and thus should be a good probe for polymer blends [44]. For quality control purposes, while the absolute or quantitative value of a given material property may not be necessary, good sensitivity to changes in that property is sufficient. In addition, a moderate time lag between sampling and measurement is acceptable. In the case of process control, the same requirements for measurements apply, but only minute time delays between sampling and obtaining the result are acceptable. Gimenez et al. [45] attempted to control bulk $\varepsilon$-caprolactone polymerization in a twin-screw extruder by modeling the process dynamics via rheological modeling coupled with RTD modeling, and using pressure measurements and in-line ultraviolet fluorescence for the experimental data. They found out that the large response time relative to the process dynamics was a limiting factor for practical process control. McAfee et al. [46] compared in-line with on-line rheometry measurements during extrusion. They concluded that the second approach is unsuitable for the dynamic control of melt viscosity, as it could not detect changes in the melt state due to temperature or shear rate effects in the extruder and did not respond to changes in feed material within the time scale required for process control. The in-line "partial Couette" flow rheometer [36] was used to control the reactive extrusion neutralization of an ethylene-methacrylic acid copolymer to produce an ionomer [14]. Nevertheless, closed loop control with on-line capillary rheometry is applied in practice, for example, to the peroxide degradation of PP, to produce different grades of material. On the other hand, process development or optimization would benefit from precise quantitative measurements of relevant material attributes, while the time lag is of little importance (as long as it does not affect the validity of the measurements).

The high investment cost of some equipment, the limited robustness of some set-ups, the need to involve specialized personnel to operate it, as well as the existing accumulated know-how on reactive extrusion control based on monitoring the conventional process parameters, seem to be delaying the widespread adoption of in-process measurement techniques. A few attempts have been made to correlate those parameters with a major material attribute, thereby generating what is denoted as a virtual softsensor. For instance, neural networking modeling techniques were adopted to define a (non-linear) relationship between process parameters and a given material property, which was measured off-line (MFR) [47]. Then, the model was applied during extrusion in order to predict the value of that property, taking in the current real values of the process parameters. The success of this methodology depends strongly on the extent of available historical data to train and test the model. With a view to automating process control, other approaches combining partial theoretical structures with data (i.e., gray-box models) were associated with fuzzy logic, neural networks, and/or genetic algorithms [48, 49]. Recently, Nguyen et al. [50] developed a closed-loop control system using a conventional proportional-integral-derivative controller that keeps the viscosity constant 
(determined from the throughput set by a gravimetric feeder and the pressure drop measured in an in-line slit die), by automatically altering the screw speed and the temperature in the first three zones of the barrel. A distinct monitoring strategy consists of mapping the output/screw speed ratio $(Q / N)$ against process parameters and selected material attributes, in order to capture the effects of processing on the latter [51]. Obviously, such mapping requires extensive extrusion trials under different processing conditions (various $Q / N$ settings), which might not be practicable in a production setting.

\subsection{In-process Optical Spectroscopy}

Radiation at different wavelengths through the spectral range (UV-Vis, IR, and Raman) induces different molecular motions. Thus, spectroscopy can provide complementary data relating to the chemical composition and structure of the skeletal backbone of a polymer. UV-Vis radiation (wavelengths between 10 and $1000 \mathrm{~nm}$ ) interacts with molecules and causes electronic transitions (promotion of electrons from the ground state to a higher energy state). These transitions at a given wavelength can be used to assess the concentration or amount of a particular species. Within the IR region of the electromagnetic spectrum (12000-400 $\mathrm{cm}^{-1}$ ), the mid-infrared (MIR) range (from 4000 to $400 \mathrm{~cm}^{-1}$ ) is associated with molecular vibrations, whereas near-infrared (NIR) (12 000-4000 $\mathrm{cm}^{-1}$ ) encompasses bands that result from harmonic overtones of fundamental and combination bands associated with hydrogen atoms (this being relevant for compounds containing $\mathrm{CH}, \mathrm{OH}$, and $\mathrm{NH}$ bonds). The Beer-Lambert law establishes a logarithmic relationship between the concentration of chemical species and absorbance, $A$ :

$$
\log A=\varepsilon c l
$$

where, $\varepsilon$ is the molar absorption coefficient of the species, $c$ is its concentration in the sample, and $l$ is the path length in the measurement cell. Thus, at constant $l$, a change in the absorbance band intensity can be associated with a change in concentration. A calibration curve is initially constructed by plotting the measured absorbance of a series of standard samples as a function of their concentration. Then, upon measuring an unknown sample by UV-Vis or MIR, the concentration of the absorbing component can be determined. Wang et al. [52] applied UV-Vis to monitor the process-induced degradation of poly-L-lactic acid (PLLA) during extrusion and found a relationship between absorption and molar mass, which was then employed to measure polymer degradation. Jakisch et al. [53] used MIR to monitor the reaction of styrene-MA copolymer with a long-chain alkyl amine in a twin-screw extruder. Although frequently utilized in many industries, application of IR to polymer melts was delayed due to the need to face high working pressures and temperatures. In-line monitoring with FTIR requires the use of the attenuated-total-reflection (ATR-IR) technique. The absorbance bands of FTIR spectra can be linked to chemical composition, but the technique requires a very short path length, as small as $50 \mu \mathrm{m}$ [23]. Thus, as the main flow channel is not this shallow, and the measurement must 

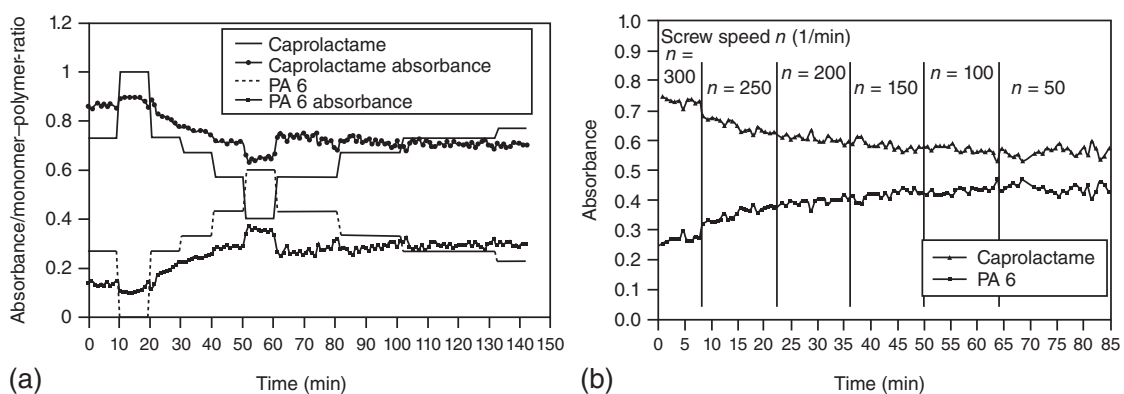

Figure 5.5 In-line monitoring of polymerization of $\varepsilon$-caprolactam in a twin-screw extruder by means of FTIR. Sensitivity of the measured absorbance to changes in time of the monomer/ polymer ratio (a) and screw speed (b). (Haberstroh et al. 2002 [56]. Reproduced with permission of Wiley.)

be representative of the bulk, on-line configurations are preferable, as used by Fritz and Ultsch [54] to follow polyethylene grafting with organosilanes. Nevertheless, in-line FTIR was applied to monitor the copolymerization of a styrene-maleic-anhydride model system with an alky-amine during melt extrusion [53]. Interestingly, the technique was also used to track reactive processes upstream of the die, a type of study that is rarely reported. The thermal degradation of polyoxymethylene (POM) during melt extrusion was analyzed on-line, via measurement of the emission of formaldehyde (FA) gas. A dome was built in the degassing section of the extruder, and pure nitrogen gas was used to carry the FA by a heated tube from the degassing section to the FTIR [55]. Haberstroh et al. [56] used ATR-FTIR to evaluate the monomer/polymer ratio during polymerization of $\varepsilon$-caprolactam in a twin-screw extruder. Measurements were performed using a high-temperature and a high-pressure resistant dipping probe with a conical two-reflection ZnSe ATR crystal mounted in the intermeshing section of the extruder, in a zone where the channels operated fully filled. The penetration depth of the IR beam in the polymer melt was about $2 \mu \mathrm{m}$. The exercise was only partially successful, since once a high polyamide concentration was reached the signal intensities became constant, probably because the layer of polyamide melt covering the ATR crystal could not be wiped out by the lower-viscous melt that had higher caprolactam content. Figure 5.5 shows the sensitivity of the measured signal to changes in time of the monomer/polymer ratio and screw speed.

The peaks in NIR spectra show considerable overlap, making quantitative analysis more difficult. Thus, the growing interest in this technique arises from the advent of highly precise instruments with very high signal to noise ratio combined with the development of multivariate analysis (also known as chemometrics), which yields a calibration model. Moreover, while optical fiber technology for the mid-IR spectral range is still expensive and susceptible to damage [23], NIR can operate with inexpensive silica fiber optics, and commercial probes are available to work either in transmission or in diffusive reflectance mode (thus enabling on-line and in-line measurements, respectively). Barbas et al. [43] used the two alternatives during compounding in twin-screw extruders and obtained 
comparable results. In-process NIR successfully monitored the composition of $\mathrm{PP} /$ ethylene vinyl acetate (EVA) copolymer blends [57], the concentration of $\mathrm{CO}_{2}$ in extrusion foaming [58], the concentration of titanium dioxide in molten PET [59], the evolution of the dispersion of organoclays in polymer melts [43, 60], and the dispersion and MFR of molten EVA copolymers [61, 62]. In reactive extrusion, Bergman et al. [63], aiming at subsequent implementation of in-line monitoring, obtained a good correlation between MW values of partly glycolized polyethylene terephthalate (PET) samples measured in diffuse reflection by NIR and by size exclusion chromatography (SEC). NIR was also used to follow the graft copolymerization of MA on to PP [64]. The technique was sensitive to the presence of vinyl $\mathrm{CH}$, but not to simple chain scission, unlike in in-line slit rheometry, which measured a decrease of the apparent viscosity. Jakisch et al. [53] analyzed the conversion of a styrene/maleic-anhydride copolymer in styrene/maleimide in a twin-screw extruder. Sasic et al. [65] monitored the chemical modification of EVA to a copolymer of ethylene-vinyl-alcohol (EVOH), while Barres et al. [66] investigated the esterification of EVOH copolymer by octanoic acid, also in a twin-screw extruder. Regrettably, these studies concentrated on validating the in-process measurements rather than demonstrating their sensitivity to practical deviations in the operating conditions or to material recipe during reactive extrusion. Figure 5.6 shows an NIR set-up developed to monitor compounding operations performed in a co-rotating twin-screw extruder, using commercial

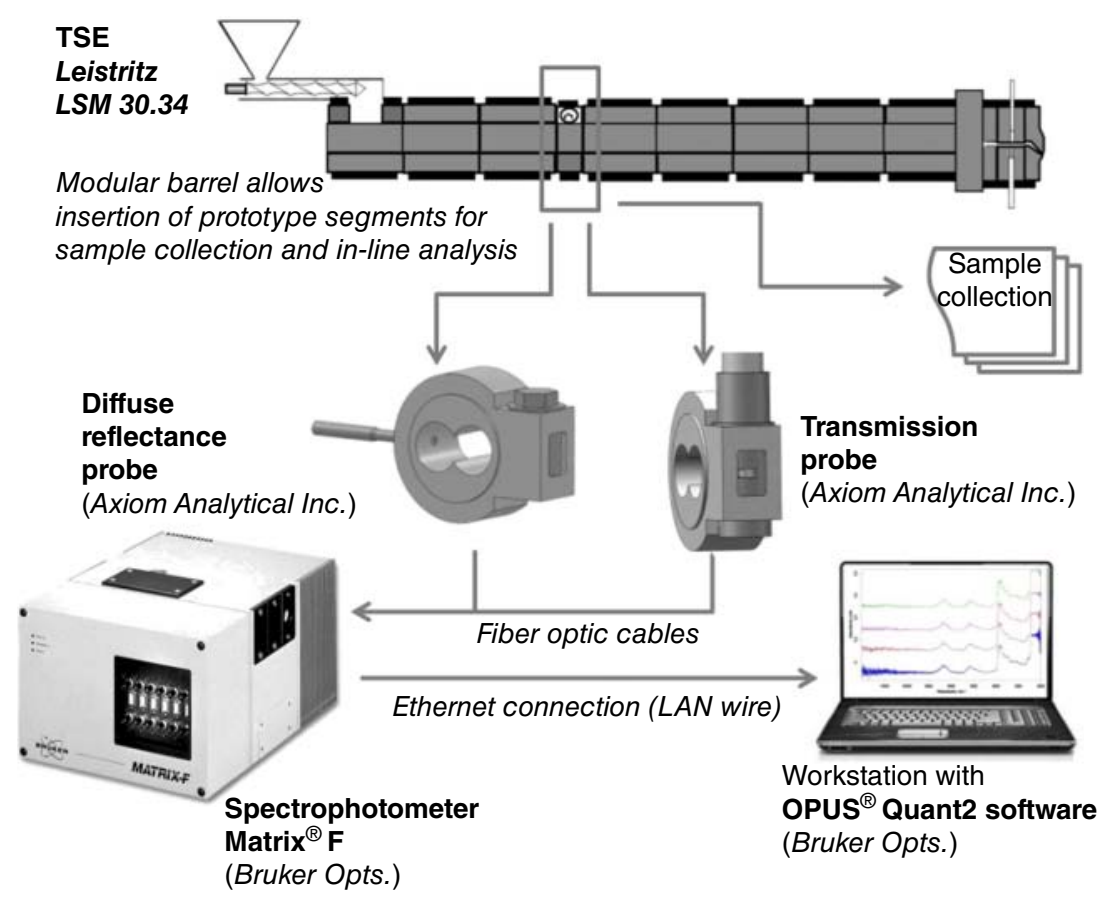

Figure 5.6 NIR set-up developed to monitor reactive extrusion in a co-rotating twin-screw extruder using commercial reflectance and transmission probes (Axiom Analytical, Inc., USA) and NIR spectrometer (Bruker Optics, Bruker Corporation). (Barbas et al. 2012 [43]. Reproduced with permission of Wiley.) 
reflectance and transmission probes (from Axiom Analytical, Inc., USA) [43]. The former is flush mounted on the barrel of the extruder (similarly to commercial melt pressure transducers), has a sapphire window with a diameter of $5.7 \mathrm{~mm}$, for an illuminated area with a diameter of $3.2 \mathrm{~mm}$ and a field depth of $3 \mathrm{~mm}$. It uses an 80-fiber bundle cable that splits into two 40-fiber bundles to connect to the analyzer inlet and outlet channels. The transmission probe is mounted on the bypass channel of a modified barrel segment, whose flow is controlled by a rotating valve. This barrel segment can be inserted between any two original barrel segments of the extruder. The probe has a rectangular gap of $5 \mathrm{~mm}$, corresponding to the optical path length. The probe's inner duct is pressurized at 4 bar with $\mathrm{N}_{2}$ to prevent humidity condensation inside the light guide channels and uses two fiber optic cables with a core fiber diameter of $600 \mu \mathrm{m}$ for transmitting and receiving signal. The set-up also comprises an NIR spectrometer (Bruker Optics, Bruker Corporation) with an InGaAs detector and a HeNe laser emitting at $633 \mathrm{~nm}$ at $1 \mathrm{~mW}$ (Bruker Optics) and a PC with software (OPUSVR Quant2) for data acquisition and analysis. This particular arrangement also allows the quick collection (in circa $1 \mathrm{~s}$ ) of material samples from within the extruder at the same location where NIR spectra are measured, which are quenched and utilized for subsequent off-line characterization.

In Raman, even though the relationship between $A$ and $c$ in Eq. (5.1) is linear, it also depends on several sample and equipment characteristics. Consequently, it is difficult to use the absolute Raman band intensity for quantitative analysis, as the intensity of the spectral band of interest is utilized instead [16]. The technique was employed for monitoring on-line the grafting of glycidyl methacrylate (GMA) on to low-density polyethylene (LDPE) in a non-intermeshing twin-screw extruder [67].

Coates et al. [16] used the aforementioned analytical tools simultaneously to monitor the single-screw extrusion of high-density polyethylene (HDPE)/PP blends and compare their performance and suitability for in-process monitoring. On-line MIR comprised 16 scans from 4400 to $400 \mathrm{~cm}^{-1}$ at a resolution of $2 \mathrm{~cm}^{-1}$, whereas on-line NIR involved 16 scans from 12000 to $4000 \mathrm{~cm}^{-1}$ at a resolution of $4 \mathrm{~cm}^{-1}$, for a collection time of approximately $30 \mathrm{~min}$. The cell path length was set to $0.01 \mathrm{~mm}$ for the MIR measurements and to $1 \mathrm{~mm}$ for the NIR measurements. In-line transmission NIR with a probe protruding into the main melt stream was performed in the range $8000-4650 \mathrm{~cm}^{-1}$; collated spectra comprised 32 scans at a resolution of $4 \mathrm{~cm}^{-1}$ and a path length of $1 \mathrm{~mm}$ (larger paths would cause excessive signal attenuation). Raman spectroscopy used a flush mounted single probe providing both excitation and signal collection. Scans of the melt were collected every minute, each consisting of a $25 \mathrm{~s}$ exposure in the 785-1080 $\mathrm{nm}$ wavelength range and the spectra were plotted in Raman shift $\left(\mathrm{cm}^{-1}\right)$ from the incident radiation (at $785 \mathrm{~nm}$ ). The required small melt path lengths of MIR (up to $\sim 0.01 \mathrm{~mm}$ ) limited its suitability for in-line testing. Although NIR signals were typically an order of magnitude smaller than those of MIR for the same melt path lengths, these could be made larger $(1-10 \mathrm{~mm}$ range) and were therefore eventually suitable for in-line testing. In fact, in this study NIR exhibited the best resolution (of $\sim 2 \mathrm{wt} \%$, i.e., changes of blend ratio of $1 \%$ were not detected). The problem remains, however, that overtones and 
combination bands are measured, making it challenging to quantify changes in specific bond vibrations in real time. In-line Raman scattering also showed good sensitivity, but the measurements involved a large fluorescent background related to additives, impurities, turbidity, temperature, and pressure effects.

NIR relies on chemometrics to extract as much significant and precise information as possible from the spectra. For polymer blending in an extruder using transmission probes, Rohe et al. [68,69] obtained deviations between predicted and actual polymer composition below $2 \%$. Chemometrics is a step-by-step procedure that aims at developing a calibration model that relates the spectral data to the reference characterization parameters [70, 71]. As schematized in Figure 5.7, it encompasses model development and validation. The multivariate calibration technique uses the entire spectral range (instead of a single spectral data point) to provide broader information and thus detect all the details of the measured spectra. To develop the calibration model (for a detailed explanation see, e.g., [72]) it is important: (i) to select carefully the parameter(s) that most adequately describe the reactive extrusion operation and that will be part of the model, (ii) to determine the minimum size of the population that is required to obtain a robust correlation, and (iii) to define the best validation/calibration population size ratio in order to minimize the monitoring time. A group of samples (commonly known as training set) is used to compute the calibration curve, which directly yields the analyte property from the respective spectra. To ensure precision, the degree of correlation between spectral and reference data should be high. For this purpose, a cross-validation step attests the quality of the adjustment of the data points to the calibration curve. A partial least squares (PLS) regression to the calibration data set is often done and the quality of the model is assessed by various measures, such as those indicated in Figure 5.7. Finally, the calibration model is ready to be used to predict the characteristics of unknown samples. Chemometrics represents both the major advantage and the constraint

Chemometric analysis
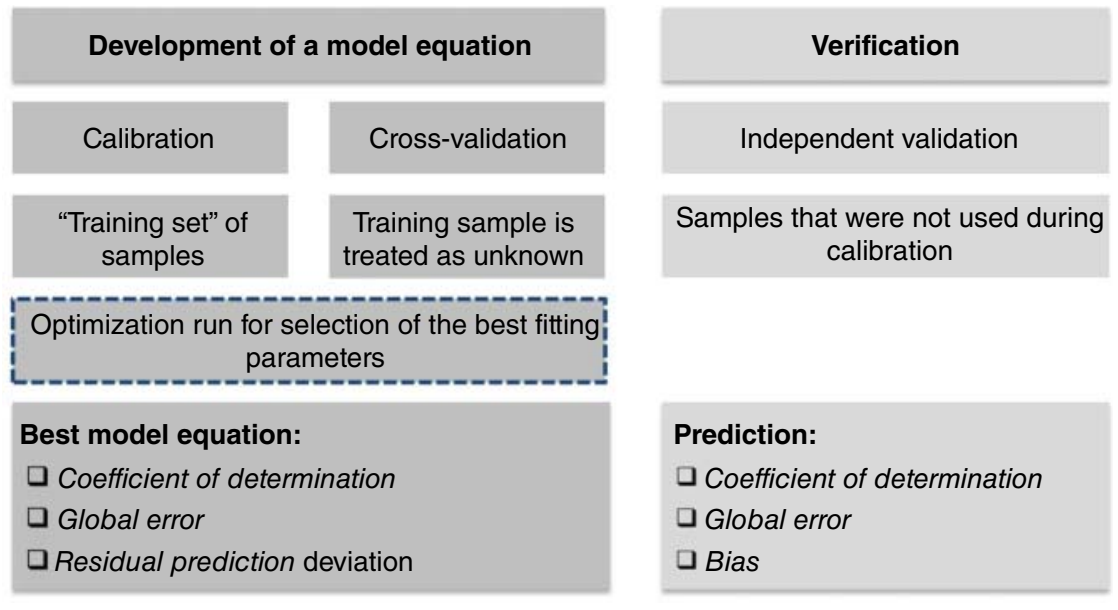

Figure 5.7 Steps for developing a chemometrical model for NIR.

Prediction:
$\square$ Coefficient of determination
$\square$ Global error
$\square$ Bias

Prediction:

$\square$ Global error

$\square$ Bias 
of NIR. Indeed, a single calibration model could eventually provide information on multiple chemical, physical, and morphological characteristics, enabling NIR to replace several other characterization techniques. However, in practice, an adequate chemometric analysis often requires extensive experimental characterization and data treatment as well as the development of multiparameter calibration models [43, 60, 70-72]. In case of the latter, it is convenient to normalize each parameter:

$$
\text { Normalized value }(\%)=\frac{\text { value }- \text { minimum }}{\text { maximum }- \text { minimum }} \times 100
$$

For example, a nil score matches the initial material, while $100 \%$ refers to total chemical conversion. In turn, each model considers the average of the relevant normalized values. It should be emphasized that since NIR spectra are sensitive both to chemical and to morphological information, a change in the material recipe or in the characteristics of the processing equipment requires a new calibration of the chemometric model.

\subsection{In-process Rheometry}

Reactive extrusion is finding increasing application in polymer blending (to manufacture polymer blends, thermoplastic elastomers (TPEs), thermoplastic vulcanizates (TPVs)), chemical modification of polymers, (bulk and graft) polymerization, depolymerization (e.g., rubber devulcanization for recycling), or new copolymer synthesis. These operations are generally aimed at manufacturing materials that have certain ranges of MW and MWD, or at generating stable and fine multiphase morphologies. Invariably, reviews of reactive extrusion or of compatibilization of immiscible polymer blends [21, 35, 73-75] contain extensive sections dealing with rheological measurements, as they are suitable for the following:

1) Acquiring an imprint of the structural and/or morphological characteristics of the initial and final materials. Extensive experimental and theoretical work covering a wide range of real-world and model polymer systems were able to establish relationships between specific rheological responses and certain material features, and rheometrical techniques and procedures were able to obtain those responses.

2) Understanding the evolution of chemical conversion or of morphology in reactive systems, including interfacial tension and dispersion levels (due to droplet deformation and breakup, coalescence, or droplet retraction).

3) Predicting the processability of the materials obtained.

4) Enabling quality control by detecting minute changes in the material characteristics.

5) Supporting automatic process control strategies.

Rheology is very sensitive to small deviations of MW (when applied to polymerization processes, rheology is often designated as rheo-kinetics or rheo-chemistry). While a variation of MW causes a change in viscosity, 
fluctuations in MWD and branching affect mainly melt elasticity. The zero shear viscosity increases with MW, while in SAOS the curves of the storage $\left(G^{\prime}\right)$ and loss $\left(G^{\prime \prime}\right)$ moduli are shifted to lower frequency with increasing MW. The maximum in $G^{\prime}$, or the $G^{\prime}, G^{\prime \prime}$ cross-over point are measures of the broadness of the distribution (for a review on rheo-kinetics of linear polymerization, see [73]). The viscosity of long-branched polymers is more shear rate dependent than that of linear polymers, and the differences in elasticity can be easily detected by measuring $G^{\prime}$ and the first normal stress difference $\left(N_{1}\right)$. Strain hardening effects of branched polymers is readily appraised by extensional viscosity measurements. In the case of immiscible polymer blends, Grace [76] made a momentous contribution toward establishing the connection between particle size and rheology, by correlating the value of the critical capillary number (i.e., the minimum value of the ratio between hydrodynamic and interfacial stresses for which droplet breakup occurs) with the viscosity ratio (disperse phase to matrix) in shear and extensional flows. Rheology is sensitive to changes in particle size, particle size distribution, volume fraction, and interfacial tension of suspensions. $G^{\prime}$ and $N_{1}$ can be used to estimate the size of dispersed droplets in a blend. Compatibilized blends are usually less shear-thinning than their uncompatibilized counterparts [21]. Steady state viscosity curves of compatibilized blends generally show two plateau regions, at low and moderate frequencies, the former stemming from interfacial rheology. Similarly, an additional slow relaxation process in SAOS on both physical and chemically compatibilized blends was attributed to interfacial elasticity. The interfacial tension can be calculated from the average relaxation time of the droplet relaxation [21].

While conventional rheological off-line measurements benefit from a wide range of available test geometries and rheometrical techniques, in-process experiments during reactive extrusion of polymer melts have been mostly confined to slit and capillary rheometry. A few commercial instruments are available. In-line slit rheometry is usually performed by coupling a rheological die to the extruder. The viscosity is calculated from readings of pressure differences along the slit, together with the determination of the throughput. Methods to quantify $N_{1}$ have also been proposed, namely the hole-pressure and the exit pressure methods. Although they are considered as valid (particularly the former), they entail experimental difficulties associated with the need of performing highly accurate experiments, which might be difficult to guarantee in an industrial environment [77]. The extensional viscosity can be estimated by linking two slits in series by a convergent channel $[78,79]$ and measuring the pressure at the entrance of the convergence, and using the well-known analysis developed by Cogswell [80] or Binding [81].

This approach has two limitations, which are typical for in-line methods. First, the viscosity is obtained at a single shear rate value, which is determined by the extrusion output. Moreover, the melt temperature might be unknown, as it is affected not only by the thermomechanical history upstream of the die, but also by viscous dissipation developing along the slit. Rauwendaal and Fernandez [82] observed that in-process measurements consistently yielded lower viscosity values than did off-line capillary and cone-and-plate rheometry. The differences were larger at higher shear rates, which was attributed to the shorter residence 


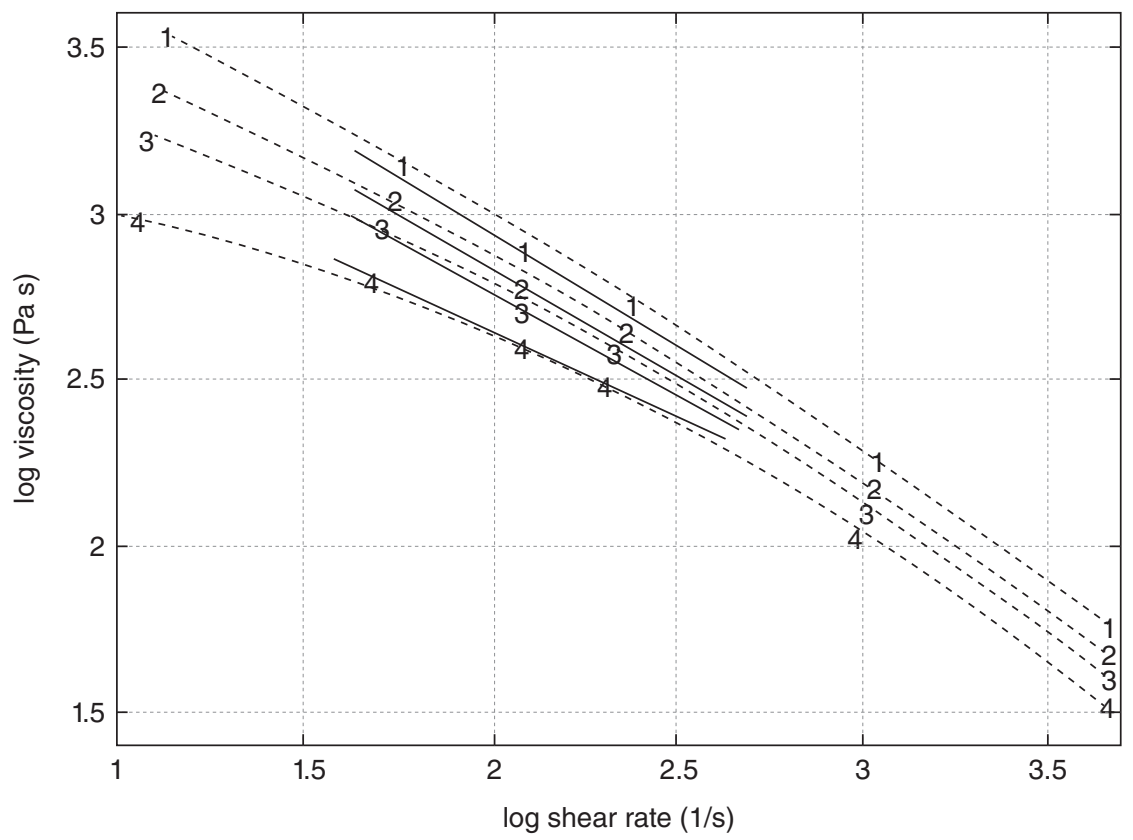

Figure 5.8 Viscosity curves of reactively degraded PP with increasing initiator concentration (curves 1-4) measured off-line (dashed lines) and in-line (solid lines) with a tapered slit. (Pabedinskas et al. 1991 [83]. Reproduced with permission of Wiley.)

times between the extruder and slit die allowing for less relaxation of the pre-shearing effects. A few constructive solutions were proposed to vary the shear rate in the measuring section, or generate different shear rates in a single measurement, under constant extrusion operating conditions. They involve the utilization of tapered slit geometries [83], of multiple-step slits with different heights but uniform width [84], and of variable gap constructions [85-87], as well as the use of flow regulators (flow valves or gear pumps) [88, 89]. In most cases, the shear rate ranges made available remain narrow. Secondly, coupling a slit die to an extruder is generally not feasible for industrial production, as it precludes the possibility of producing extrudates with non-rectangular cross-section. Thus, this type of set-up is mostly adopted for R\&D purposes. Figure 5.8 compares the viscosity curves of reactively degraded PP measured off-line and in-line with a tapered slit [83].

On-line capillary or slit rheometers, either coupled to the die or between extruder and die, are preferred for industrial compounding and reactive extrusion. Comparisons between in-line, on-line, and off-line [90] and between on-line and off-line [38] rheometry have generally shown good agreement, but were performed with thermally stable polymers. The design, complexity, and compactness of these devices vary, and so do the range of attainable viscosities and shear rates (in some instruments, above $10^{5} \mathrm{~s}^{-1}$ ), the time delay between 


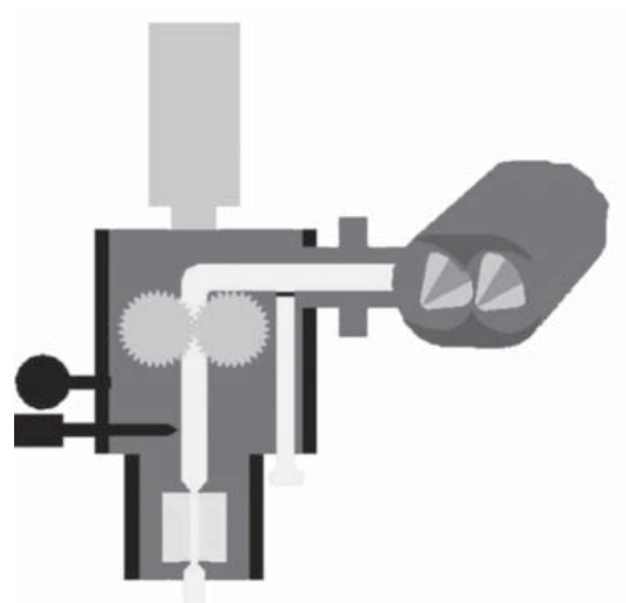

(a)

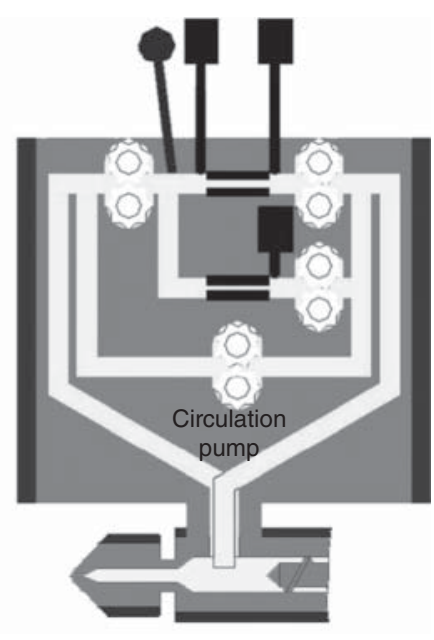

(b)

Figure 5.9 On-line capillary rheometers from GÖTTFERT Werkstoff-Prüfmaschinen GmbH, Germany. (a) Compact on-line rheometer without melt return into the process (note also the purge valve); (b) on-line instrument with melt return and bypass with continuous circulating volume stream.

sample collection and measurement, and whether the sampled material is wasted or returned to the main flow (sampling rates vary typically between 0.5 to a few kilograms per hour). An on-line extensional rheometer of the filament stretching-type has also been developed [91]. Figure 5.9 displays two on-line capillary rheometers supplied by the same manufacturer (GÖTTFERT Werkstoff-Prüfmaschinen $\mathrm{GmbH}$, Germany). One is a compact single-bore instrument, designed for processes with frequent product changes (so, quick die replacement is essential) and without melt return capacity. A material stream is detoured from the main channel and conditioned to the required testing temperature. A gear pump then accurately controls the flow rate in the testing chamber, where the pressure drop is measured. The other model in the figure is a twin-bore rheometer that returns the sampled melt to the main flow and has an independent material circulation system to deliver the melt to the parallel capillaries quickly (thus avoiding slower transfers for low viscosity systems). Melt flow through parallel capillaries (up to 4, depending on the model and manufacturer) of the same size but with distinct length allows performing the well-known Bagley correction for end effects, while using different diameters yields multiple points of the viscosity flow curve. Flow through these dies can be simultaneous or sequential (so that less amount of material is consumed in the measurements), in which case a melt switch or a rotating valve is used. Further, extensional viscosities can be estimated if a "zero length" die (i.e., a very short die, whose pressure drop is essentially due to entrance effects) is fixed as one of the capillaries. An optical window may also exist, so that other on-line techniques (e.g., NIR-UV-Vis) are used simultaneously. Some systems can 
also operate at constant pressure (corresponding to a certain shear stress) and determine the resulting flow rate (from the knowledge of the rpm of the gear pump, its volume per revolution, and the melt density at the test temperature). In this mode, it becomes possible to measure MFR: from the test load defined by the relevant standard (e.g., ASTM D-1238 or ISO 1133) the working pressure is set; knowing the flow rate, the MFR is calculated. A few apparatuses have an interchangeable measuring geometry, enabling a choice between slit and capillary viscometry. Capillaries seem to be more frequently used than slits, as they are easier to clean (no edges), can provide a wider measuring range under moderate pressures, and are geometrically more similar to the MFR test. Nonetheless, an interesting design consists of a die that divides the inlet flow into two parallel geometrically identical slits, one of them being used for the measurements [92]. The distribution of the flow is controlled by vertically moving the valves located at the entrance of each channel. The shear rate at the measuring slit can be altered by adjusting the respective valve and rotating the other valve in the opposite direction, so that the total pressure drop remains constant and so does the thermomechanical environment of the polymer in the extruder. The concept was revisited by Vergnes et al. [93] and was recently adopted in a modified form $[87,94]$.

On-line capillary rheometry measurements along the extruder are much scarcer. Covas et al. [38] designed a device that can be fixed at various locations along the extruder. As illustrated in Figure 5.10, it essentially comprises a modified barrel element (in this case, of a Leistritz LSM 30.34 twin-screw extruder), the measuring head of a commercial rotational rheometer, the heated body, piston, and replaceable die of the capillary instrument. The barrel element contains a lateral circular channel that links the inner barrel wall to the reservoir of the rheometer through a lateral hole in its body whereby proper alignment is

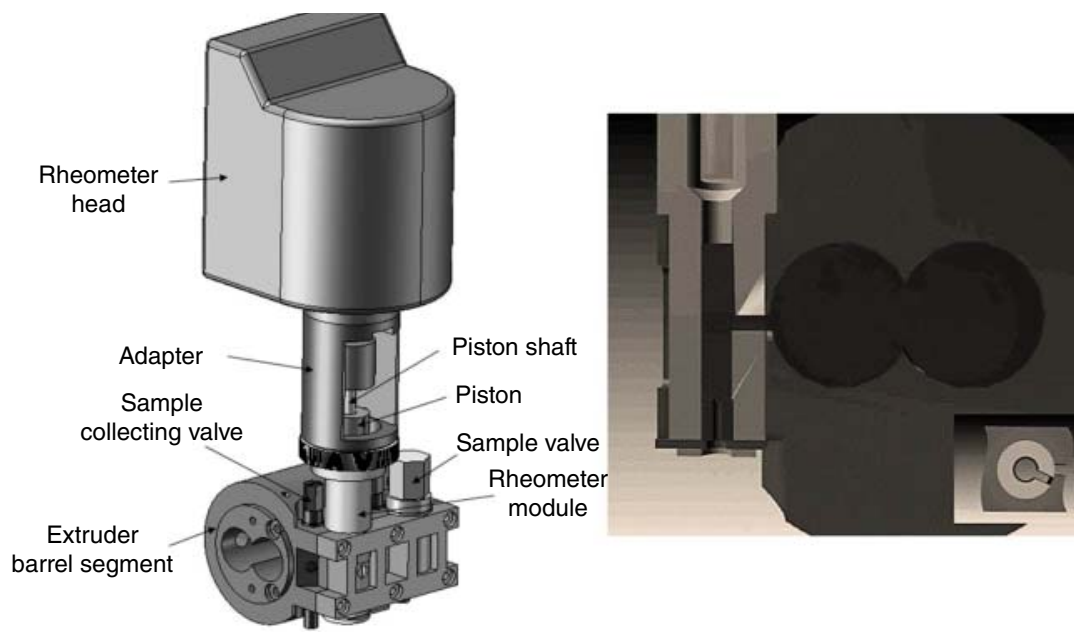

Figure 5.10 On-line capillary rheometer with modified barrel element to be inserted in between standard elements of a twin-screw extruder. 
guaranteed. This is controlled by the rotation of the entire rheometer module around its vertical axis. Thus, a rheological measurement entails the following sequence: (i) fix the desired die and set test temperature; (ii) rotate the rheometer module until full alignment with the lateral channel of the barrel element is achieved; (iii) once the material flowing from within the extruder has filled the reservoir between the piston and die, rotate the module again to isolate the rheometer from the extruder; (iv) wait for thermal equilibration; (v) start the test - the rotational movement of the rheometer shaft is converted into a linear vertically descending piston movement, while the torque is recorded and used to determine the apparent wall shear rate and stress, respectively. The usual Bagley and Rabinowitsch corrections to the data (due to entrance and exit effects and due to the non-parabolic velocity profile of non-Newtonian fluids, respectively [42]) are performed in order to yield true values of the wall shear rate and stress. A modified version of the instrument allowed for the on-line measurement of MVR in accordance with the ASTM D-1238 and ISO 1133 standards [95].

This prototype was used to follow the peroxide-induced degradation of PP $[96,97]$. Figure 5.11 reveals the influence of peroxide content (2,5-bis(tertbutylperoxy)-2,5-dimethylhexane (DHBP)) on the evolution of shear viscosity along the barrel of the extruder at constant operating conditions. As expected, the higher the peroxide content, the lower is the resulting viscosity. The degradation reaction occurs very quickly and very early in the extruder. For example, when $0.05 \mathrm{phr}$ of DHBP was added to PP, as the melt reached the first kneading block at $L / D=9$ (most pellets remained solid at $L / D=8$ ) the reaction seemed to have already attained high conversion levels. Even when the peroxide content was augmented to $0.1 \mathrm{phr}$, the reaction was all but complete at the end of this first kneading block, at $L / D=11$. The MWD of PP was measured by gel-permeation chromatography (GPC), using samples collected at the same axial locations. The results unveiled an excellent correlation between MW and viscosity changes, but showed a relative lack of sensitivity of capillary rheometry to changes in MWD.

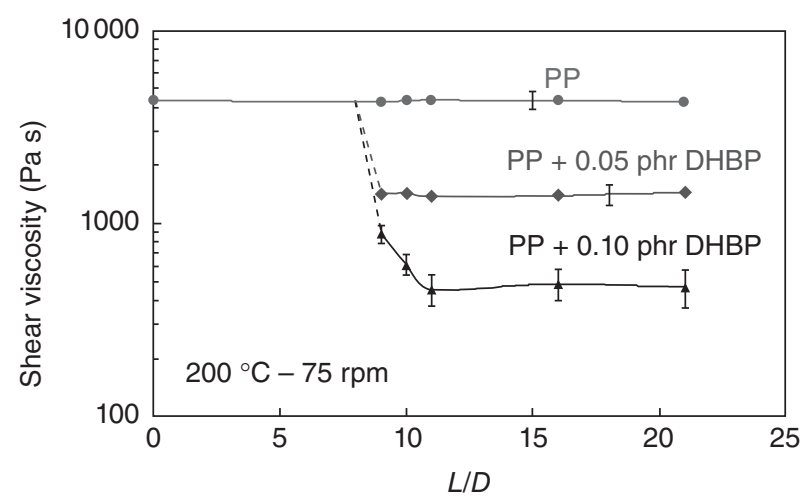

Figure 5.11 Effect of peroxide concentration on shear viscosity of PP + DHDP along a co-rotating twin-screw extruder. (Adapted from Machado et al. 2004 [97]. Reproduced with permission of Wiley.) 
Practice demonstrated that oscillatory rheometry is the preferred method to characterize multiphase systems, because - unlike capillary rheometry - it preserves the initial material morphology (due to the small deformation amplitudes involved), is sensitive to minor variations in droplet or particle size, and can generate a rather complete rheological description. In-line vibrating probe viscometers are generally designed for installation in pipe elbows or in vessels, typically to monitor polymerization reactions (either in batch or prior to extrusion). Commercial on-line oscillatory rheometers (with parallel plate geometry) are available, but their operational window makes them suitable for studying lubricating greases, inks and paints, foodstuff, household products and cosmetic and personal care products. A Piezo Axial Vibrator was developed aiming at on-line measurements in extrusion. It generates an axial oscillation on a molten polymer sample and converts the signal into the rheological moduli $G^{\prime}$ and $G^{\prime \prime}$. However, preliminary validation tests demonstrated that robustness and handling should be improved [98]. Covas et al. [39, 99, 100] designed an on-line rotational rheometer with sensing capabilities and measuring modes similar to those of conventional laboratory instruments. With or without a modified barrel element, tests could be carried out along the axis of an extruder, or between extruder and die, respectively. Figure 5.12 depicts the set-up for measurements along the extruder, the configuration adopted for coupling to the flow channel between extruder and die, and the operating sequence. The system uses a plate-plate configuration and comprises a motor to control the position of the lower plate, a motor to open/close the valve admitting the material sampled, a linear actuator to control the movement of a ring cleaning the outer surface of the test sample, and a commercial rotational rheometer head (Figure 5.12A). The set-up is connected to the flow channel between extruder and die by a vibration-damping coupling, and the flow is controlled by a rotating valve (Figure 5.12B). As for the operating sequence, the cycle begins by assuming that the extruder is operating normally, with the rheometer ready to operate (a). Upon rotating the valve (b), melt from the extruder flows to the testing chamber. When enough material is sampled, the valve closes (c). The material is then squeezed between the two plates, in order to define the pre-set gap (d). The cleaning ring wipes out the excess material (e). After the necessary thermal equilibration time, the test starts. The preparatory steps of each experiment are controlled by a program written in LabVIEW System Design Software, whereas the rheometer software controls the test. Validation of the instrument encompassed comparisons between on-line and off-line measurements of polyolefins and a compatibilized polymer blend (polyamide 6/polyethylene-grafted-maleic anhydride (PA6/PE-g-MA)). Both provided very good agreement [39]. The evolution of the rheological properties of a polyamide $6 /$ low-density polyethylene immiscible blend (PA6/LDPE) $(70 / 30 \mathrm{w} / \mathrm{w} \%)$ and of a PA6/LDPE/maleic anhydride-grafted-polyethylene (PA6/PE/PE- $g$-MA) (70/15/15w/w\%)) blend was then followed both on-line and off-line (using samples collected at the same locations and immediately quenched in liquid nitrogen) [39]. The second blend maintains the proportion of PA6, but half of the LDPE was replaced by PE- $g$-MA. 

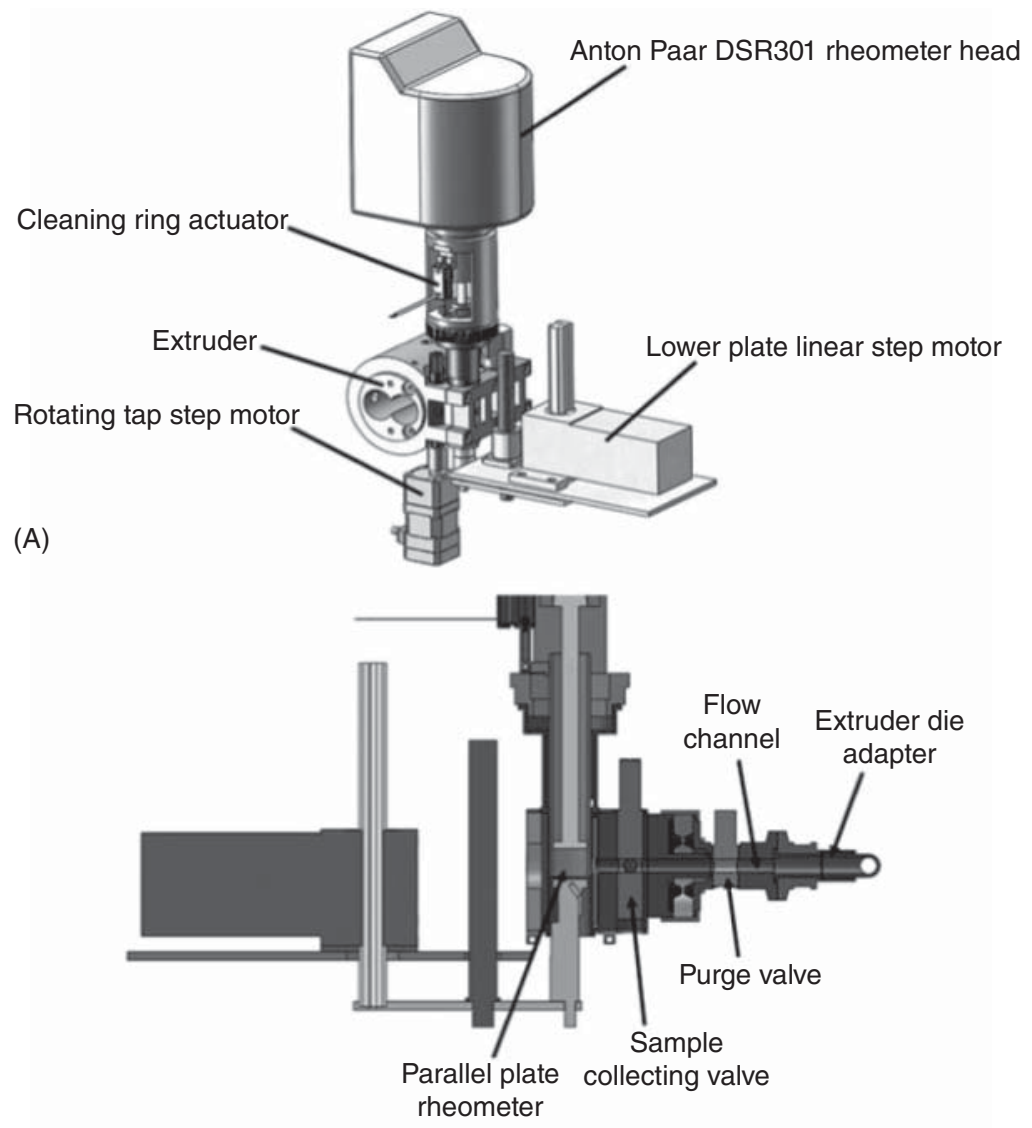

(B) chamber
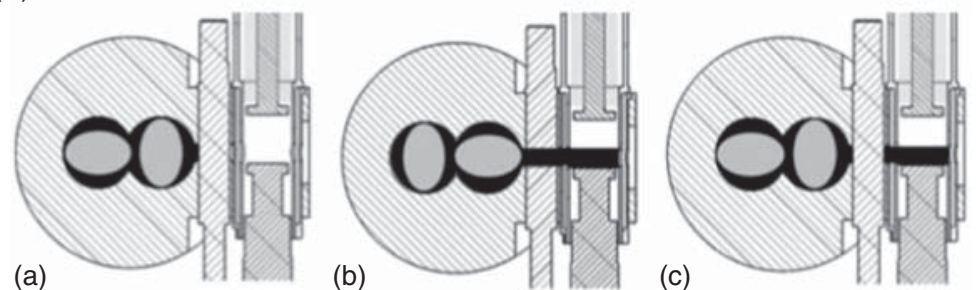

(b)

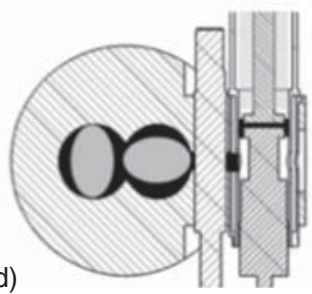

(c)

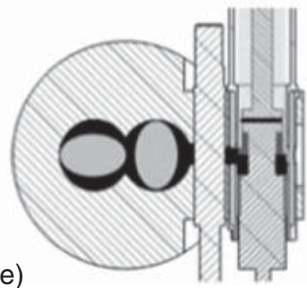

(C)

(d)

Figure 5.12 On-line rotational rheometer. From A to C: global set-up for measurements along the extruder; configuration adopted for coupling to the flow channel between extruder and die; operating sequence. (Mould et al. 2012 [100]. Reproduced with permission of Carl Hanser Verlag GmbH \& Co. KG.) 


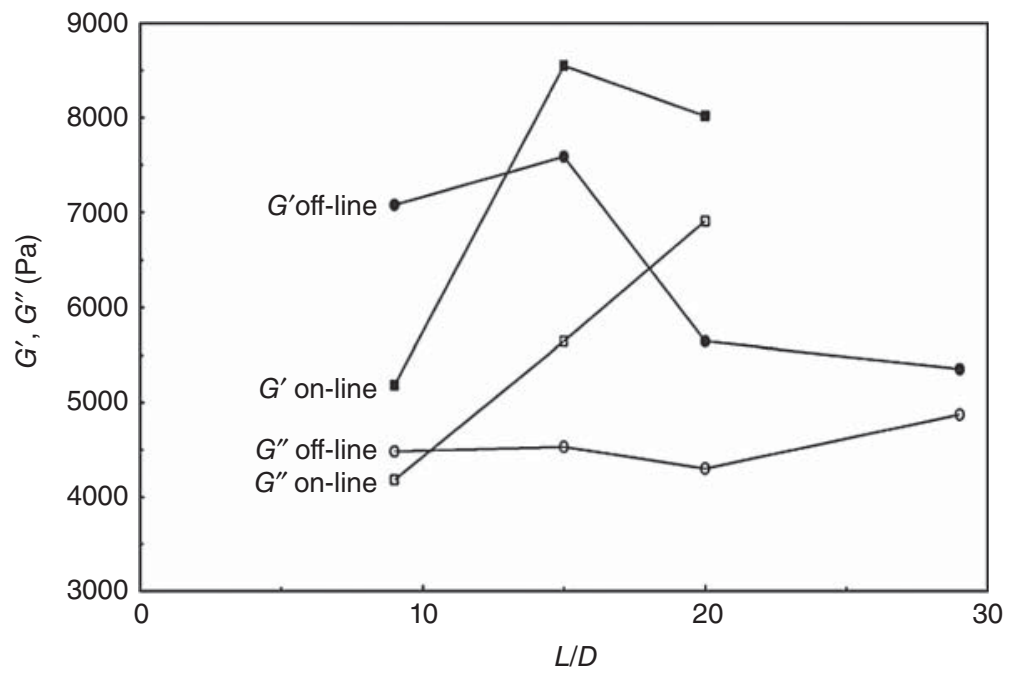

Figure 5.13 Evolution of $G^{\prime}$ and $G^{\prime \prime}\left(\right.$ at $1 \mathrm{~s}^{-1}$ ) of a PA6/PE/PE-g-MA (70/15/15 w/w\%) blend along the axis of a co-rotating twin-screw extruder, measured off-line and on-line. (Covas et al. 2008 [39]. Reproduced with permission of Elsevier.)

Therefore, the amine groups of PA6 react with the MA groups of the modified PE to form a copolymer at the interface, which acts as a compatibilizer. In the case of the PA6/LDPE blend, the extra thermal cycles imparted on the off-line samples (due to manufacturing of a disk by compression molding and heating it for the rheological test) had a dramatic effect on their thermal stability, unlike that observed in the data obtained on-line. The evolution of the viscoelastic response was also quantitative and qualitatively different. Micrograph images of the material after sampling and after compression molding exhibited quite different morphologies. In the case of the compatibilized blend, the on-line and off-line responses were again dissimilar, although the differences are smaller. This was undoubtedly due to the morphology stabilization effect of the copolymer, which minimized the influence of compression molding. Nevertheless, as perceived in Figure 5.13, which shows the evolution along the extruder of $G^{\prime}$ and $G^{\prime \prime}$ at fixed frequency $\left(1 \mathrm{~s}^{-1}\right)$, the extra thermal cycles suffered by off-line samples artificially reduce the differences along the extruder. Indeed, $G^{\prime \prime}$ is nearly constant in the samples tested off-line, whereas on-line tests detected a significant increase between $L / D=9$ and $L / D=20 . G^{\prime}$ seems to increase and then gradually decrease, probably due to thermal degradation. Although more experiments are necessary to support these observations, on-line rheology often detects a progressive degradation of some polymers once the chemical reaction has achieved high levels of conversion. Figure 5.14 plots the complex viscosity, $\left(\eta^{*}\right)$ and $G^{\prime}$ at three locations along the extruder for a PLA plus chain extender system. The reaction was fast and took place upon melting of the polymer and a gradual decrease in viscosity was detected. 

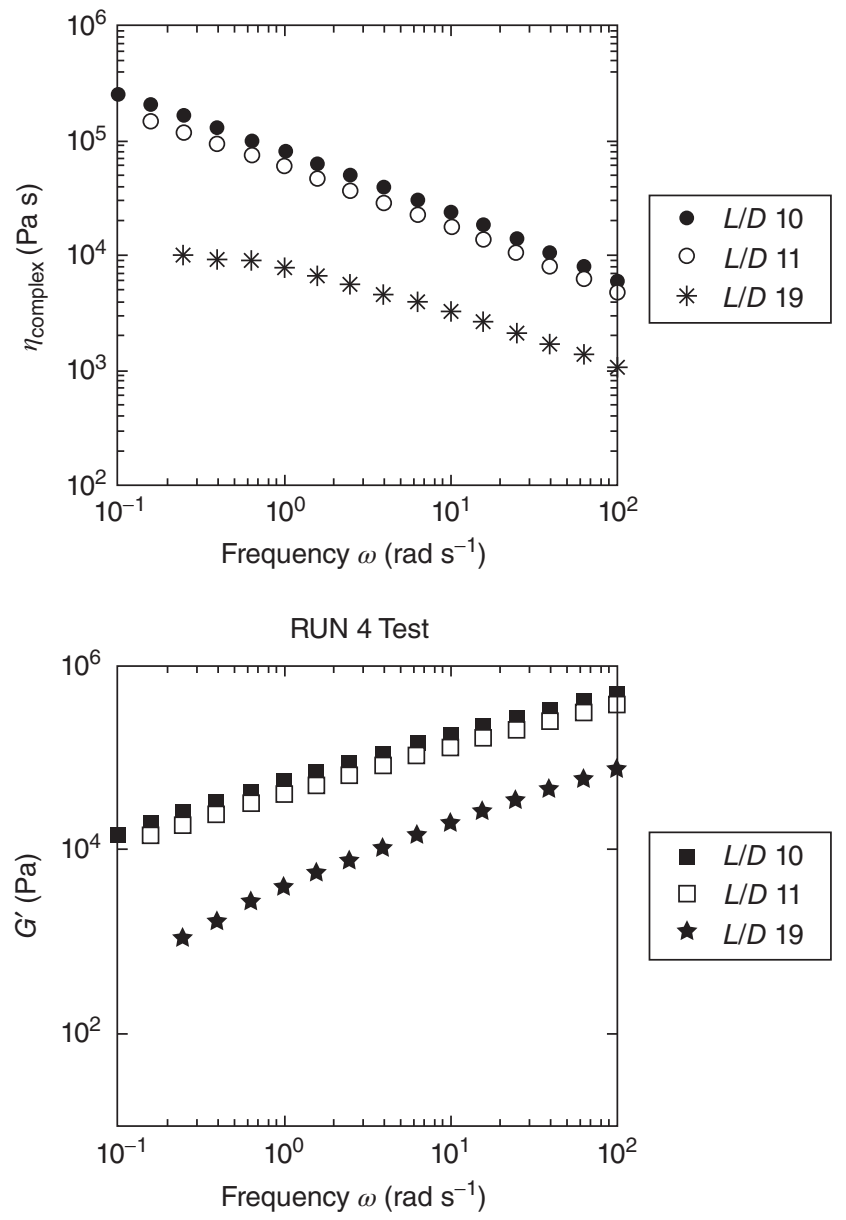

Figure 5.14 Evolution of the linear viscoelastic response of a PLA and chain extender system along the axis of a co-rotating twin-screw extruder (unpublished data).

\subsection{Conclusions}

The potential of in-process monitoring has not been fully explored. However, mainly in the past two decades, a significant effort has been made by the academic and industrial communities to develop in-process monitoring techniques that are capable of obtaining qualitative or quantitative data on a wide range of characteristics and properties of polymeric systems at various scales. Signal to noise ratio, precision, time lag between sampling and result, reproducibility, robustness, and operational window have largely improved. The choice of an in-process method for a given reactive extrusion process from the array of current possibilities that are available must take into consideration the purpose of the application, the geometry of the probe, and the mounting possibilities provided 
by the processing equipment. Thus the utilization of these techniques to support $\mathrm{R} \& \mathrm{D}$ activity, quality control, and, progressively, process control, is expected to rise substantially.

\section{Acknowledgment}

The author acknowledges Prof. Ana V. Machado for the interesting discussions concerning in-process optical spectroscopy.

\section{References}

1 van Duin, M., Machado, A.V., and Covas, J.A. (2001) A look inside the extruder: evolution of chemistry, morphology and rheology along the extruder axis during reactive processing and blending. Macromol. Symp., 170, 21.

2 Covas, J.A. and Machado, A.V. (2005) Monitoring reactive processes along the extruder. Int. Polym. Proc., XX, 121.

3 Isac, S.K. and George, K.E. (2001) Reactive processing of polyethylenes on a single screw extruder. J. Appl. Polym. Sci., 81, 2545.

4 Tzoganakis, C. (1989) Reactive extrusion of polymers: a review. Adv. Polym. Tech., 9, 321.

5 Mack, W.A. and Herter, R. (1976) Extruder reactors for polymer production. Chem. Eng. Progr., 72, 64.

6 Van Der Goot, A.J., Hettema, R., and Jansen, L.P.B.M. (1997) The working domain in reactive extrusion. Part I: the effect of the polymer melt viscosity. Polym. Eng. Sci., 37, 511.

7 Kohlgruber, K. (ed.) (2008) Co-rotating Twin-Screw Extruders, Carl Hanser, Munich.

8 Machado, A.V., Covas, J.A., and van Duin, M. (1999) Evolution of morphology and of chemical conversion along the screw in a corotating twin screw extruder. J. Appl. Polym. Sci., 71, 135.

9 Machado, A.V., Covas, J.A., and van Duin, M. (1999) Chemical and morphological evolution of PA6/EPM/EPM- $g$-MA blends in a twin screw extruder. J. Polym. Sci., 37, 1311.

10 Machado, A.V., Covas, J.A., and van Duin, M. (2001) Monitoring polyolefin modification along the axis of a twin screw extruder. I - Effect of peroxide concentration. J. Appl. Polym. Sci., 81, 58.

11 Machado, A.V., Yquel, V., Covas, J.A., Flat, J.-J., Ghamri, N., and Wollny, A. (2006) The effect of the compatibilization route of PA/PO blends on the physico-chemical phenomena developing along a twin-screw extruder. Macromol. Symp., 233, 86.

12 Canto, L.B., Mantovani, G.L., Covas, J.A., Hage, E. Jr., and Pessan, L.A. (2007) Phase morphology development during processing of compatibilized and uncompatibilized PBT/ABS blends. J. Appl. Polym. Sci., 104, 102. 
13 Yquel, V., Machado, A.V., Covas, J.A., and Flat, J.J. (2009) The contribution of the melting stage to the evolution of morphology and chemical conversion of immiscible PA/PE blends in twin screw extruder. J. Appl. Polym. Sci., 114, 1768.

14 Broadhead, T.O., Patterson, W.I., and Dealy, J.M. (1996) Closed loop viscosity control of reactive extrusion with an in-line rheometer. Polym. Eng.Sci., 36, 2840.

15 Fritz, H.-G. and Stöhrer, B. (1986) Polymer compounding process for controlled peroxide-degradation of PP. Int. Polym. Proc., 1, 31.

16 Coates, P.D., Barnes, S.E., Sibley, M.G., Brown, E.C., Edwards, H.G.M., and Scowen, I.J. (2003) In-process vibrational spectroscopy and ultrasound measurements in polymer melt extrusion. Polymer, 44, 5937.

17 Barnes, S.E., Sibley, M.G., Edwards, H.G.M., and Coates, P.D. (2007) Process monitoring of polymer melts using in-line spectroscopy. Trans. Inst. Measur. Control, 29, 453.

18 Migler, K.B. and Bur, A.J. (1998) Fluorescence based measurement of temperature profiles during polymer processing. Polym. Eng. Sci., 38, 213.

19 Carneiro, O.S., Covas, J.A., Ferreira, J.A., and Cerqueira, M.F. (2004) On-line monitoring of the residence time distribution along a kneading block of a twin-screw extruder. Polym. Testing, 23, 925.

20 Teixeira, P.F., Covas, J.A., Maia, J.M., and Hilliou, L. (2014) In-line particle size assessment of polymer suspensions during processing. Polym. Testing, 37, 68.

21 Van Puyvelde, P.V. and Moldenaers, P. (2005) Rheology and morphology development in immiscible polymer blends. Rheol. Rev., 2005, The British Soc. Rheology, 101.

22 Migler, K.B., Hobbie, E.K., and Qiao, F. (1999) In line study of droplet deformation in polymer blends in channel flow. Polym. Eng. Sci., 39, 2282.

23 Alig, I., Steinhoff, B., and Lellinger, D. (2010) Monitoring of polymer melt processing. Meas. Sci. Technol., 21, 062001.

24 Schlatter, G., Serra, C., Bouquey, M., Muller, R., and Terrisse, J. (2002) Online light scattering measurements: a method to assess morphology development of polymer blends in a twin-screw extruder. Polym. Eng. Sci., 42, 1965.

25 Xian, G.-M., Qu, J.-P., and Zeng, B.-Q. (2008) An effective on-line polymer characterization technique by using SALS image processing software and wavelet analysis. J. Aut. Meth. Manag. Chem., 2008, ID 838412.

26 Bur, A.J., Lee, Y.-H., Roth, S.C., and Start, P.R. (2005) Measuring the extent of exfoliation in polymer/clay nanocomposites using real-time process monitoring methods. Polymer, 46, 10908.

27 Cunha Santos, A.M., Cáceres, C.A., Calixto, L.S., Zborowski, L., and Canevarolo, S.V. (2014) In-line optical techniques to characterize the polymer extrusion. Polym. Eng. Sci., 54, 386.

28 Soares, K., Cunha Santos, A.M., and Canevarolo, S.V. (2011) In-line rheo-polarimetry: a method to measure in real time the flow birefringence during polymer extrusion. Polym. Testing, 30, 848. 
29 Kiehl, C., Chu, L.-L., Leitz, K., and Min, K. (2001) On-line ultrasonic measurements of methyl methacrylate polymerization for application to reactive extrusion. Polym. Eng. Sci., 41, 1078.

30 Kotzé, R., Wiklund, J., and Haldenwang, R. (2013) Optimisation of pulsed ultrasonic velocimetry system and transducer technology for industrial applications. Ultrasonics, 53, 459.

31 Perusich, S. and McBrearty, M. (2000) Dielectric spectroscopy for polymer melt composition measurements. Polym. Eng. Sci., 40, 214.

32 Boersma, A. and van Turnhout, J. (1999) Dielectric on-line spectroscopy during extrusion of polymer blends. Polymer, 40, 5023.

33 Dealy, J.M. and Broadhead, T.O. (1993) Process rheometers for molten plastics: a survey of existing technology. Polym. Eng. Sci., 33, 1513.

34 Saerens, L., Vervaet, C., Remon J.-P., De Beer, T. (2014) Process monitoring and visualization solutions for hot-melt extrusion: a review, J. Pharm. Pharmacol., 66, 180.

35 Cassagnau, P., Bounor-Legaré, V., and Fenouillot, F. (2007) Reactive processing of thermoplastic polymers: a review of the fundamental aspects. Int. Polym. Proc., XXII, 219.

36 Broadhead, T.O., Nelson, B.I., and Dealy, J.M. (1993) An in-line rheometer for molten plastics: design and steady state performance characteristics. Int. Polym. Proc., 8, 104.

37 Dealy, J.M. (1990) Challenges in process rheometry. Rheol. Acta, 29, 519.

38 Covas, J.A., Nóbrega, J.M., and Maia, J.M. (2000) Rheological measurements along an extruder with an on-line capillary rheometer. Polym. Testing, 19, 165.

39 Covas, J.A., Maia, J.M., Machado, A.V., and Costa, P. (2008) On-line rotational rheometry for extrusion and compounding operations. J. Non-Newt. Fluid Mech., 148, 88.

40 Dealy, J.M. and Rey, A. (1996) Effect of Taylor diffusion on the dynamic response of a on-line capillary viscometer. J. Non-Newt. Fluid Mech., 62, 225.

41 Dealy, J.M. (1984) Viscometers for online measurement and control. Chem. Eng., 91, 62.

42 Macosko, C.W. (1994) Rheology - Principles, Measurements, and Applications, Wiley-VCH.

43 Barbas, J.M., Machado, A.V., and Covas, J.A. (2012) In-line near-infrared spectroscopy: a tool to monitor the preparation of polymer-clay nanocomposites in extruders. J. Appl. Polym. Sci., 127, 4899.

44 Levitt, L., Macosko, C.W., Schweizer, T., and Meissner, J. (1997) Extensional rheometry of polymer multilayers: a sensitive probe of interfaces. J. Rheol., 41, 671.

45 Gimenez, J., Boudris, M., Cassagnau, P., and Michel, A. (2000) Control of bulk $\varepsilon$-caprolactone polymerization in a twin screw extruder. Polym. React. Eng., 8, 135.

46 McAfee, M., Thompson, S., and McNally, G.M. (2004) In-Process Viscosity Monitoring for Extrusion Control. SPE-ANTEC 2014, 1274. 
47 Yiagopoulos, T., Schmidt, C.-U., and Marelli, E. (2001) Development of a softsensor for on-line MFI monitoring in reactive polypropylene extrusion. Dech. Monogr., Wiley-VCH Verlag, 138, 305.

48 Liu, X., Li, K., McAfee, M., and Deng, J. (2010) 'Soft-sensor' for Real-time Monitoring of Melt Viscosity in Polymer Extrusion Process. 49th IEEE Conference Decision and Control, December 15-17, Atlanta, GA, USA, 3469.

49 Liu, X., Li, K., McAfee, M., Nguyen, B.K., and McNally, G.M. (2012) Dynamic grey-box modeling for on-line monitoring of polymer extrusion viscosity. Polym. Eng. Sci., 52, 1332.

50 Nguyen, B.K., McNally, G.M., and Clarke, A. (2014) Real time measurement and control of viscosity for extrusion processes using recycled materials. Polym. Degrad. Stab., 102, 212.

51 Wetzel, M.D., Avgousti, M., Denelsbeck, D.A., and Latimer, S.L. (2007), Reactive Extrusion Process Characterization: Q/N Mapping Method. SPE-ANTEC 2007, 464.

52 Wang, Y., Steinhoff, B., Brinkmann, C., and Alig, I. (2008) In-line monitoring of the thermal degradation of poly(L-lactic acid) during melt extrusion by UV-vis spectroscopy. Polymer, 49, 1257.

53 Jakisch, L., Fischer, D., Stephan, M., and Eichhorn, K.J. (1995) In-lineanalytik von polymerreaktionen. Kunststoffe, 85, 1338.

54 Fritz, H.-G. and Ultsch, S. (1989) Sensorentwicklung und Automatisierungstendenzen bei der Kunststoffaufbereitung. Kunststoffe, 79, 785.

55 Rajan, V.V., Waber, R., and Wieser, J. (2010) Online monitoring of the thermal degradation of POM during melt extrusion. J. Appl. Polym. Sci., 115, 2394.

56 Haberstroh, E., Jakisch, L., Henuge, E., and Schwarz, P. (2002) Real-time monitoring of reactive extrusion processes by means of in-line infrared spectroscopy and infrared temperature measurement. Macromol. Mat. Eng., 287, 203.

57 Fischer, D., Bayer, T., Eichhorn, K.-J., and Otto, M. (1997) In-line process monitoring on polymer melts by NIR-spectroscopy. J. Analyt. Chem., 359, 74.

58 Nagata, T., Tanigaki, M., and Ohshima, M. (2000) On-line NIR sensing of $\mathrm{CO}_{2}$ concentration for polymer extrusion foaming processes. Polym. Eng. Sci., 40, 1843.

59 Batra, J., Khettry, A., and Hansen, M.G. (1994) In-line monitoring of titanium dioxide content in poly(ethylene terephthalate) extrusion. Polym. Eng. Sci., 34, 1767.

60 Barbas, J.M., Machado, A.V., and Covas, J.A. (2013) Evolution of dispersion along the extruder during the manufacture of polymer-organoclay nanocomposites. Chem. Eng. Sci., 98, 77.

61 Vedula, S. and Hansen, M.G. (1998) In-line fiber-optic near-infrared spectroscopy: monitoring of rheological properties in an extrusion process. Part I. J. Appl. Polym. Sci., 68, 859.

62 Vedula, S. and Hansen, M.G. (1998) In-line fiber-optic near-infrared spectroscopy: monitoring of rheological properties in an extrusion process. Part II. J. Appl. Polym. Sci., 68, 873. 
63 Bergmann, B., Becker, W., Diemert, J., and Elsner, P. (2013) On-line monitoring of molecular weight using NIR spectroscopy in reactive extrusion process. Macromol. Symp., 333, 138.

64 Moghaddam, L., Rintoul, L., Halley, P.J., George, G.A., and Fredericks, P.M. (2012) In-situ monitoring by fibre-optic NIR spectroscopy and rheometry of maleic anhydride grafting to polypropylene in a laboratory scale reactive extruder. Polym. Testing, 31, 155.

65 Sasic, S., Kita, Y., Furukawa, T., Watari, M., Siesler, H.W., and Ozaki, Y. (2000) Monitoring the melt-extrusion transesterification of ethylenevinylacetate copolymer by self-modeling curve resolution analysis of on-line near-infrared spectra. Analyst, 125, 2315.

66 Barres, C., Bounor-Legaré, V., Mélis, F., and Michel, A. (2006) In-line near infrared monitoring of esterification of a molten ethylene-vinyl alcohol copolymer in a twin screw extruder. Polym. Eng. Sci., 46, 1613.

67 Jarukumjorn, K. and Min, K. (2000) On-Line Monitoring of Free Radical Grafting in a Model Twin Screw Extruder. SPE ANTEC 2000, 2064.

68 Rohe, T., Becker, W., Krey, A., Nägele, H., Kölle, S., and Eisenreich, N. (1998) In-line monitoring of polymer extrusion processes by NIR spectroscopy. J. Near Infrared Spectrosc., 6, 325.

69 Rohe, T., Becker, W., Kolle, S., Eisenreich, N., and Eyerer, P. (1999) Near infrared (NIR) spectroscopy for in-line monitoring of polymer extrusion processes. Talanta, 50, 283.

70 Blanco, M. and Villarroya, I. (2002) NIR spectroscopy: a rapid-response analytical tool. Trends Anal. Chem., 21, 240.

71 Siesler, H.W., Ozaki, Y., Kawata, S., and Heise, H.M. (2002) Near-Infrared Spectroscopy: Principles, Instruments, Applications, Willey-VCH.

72 Barbas, J.M., Machado, A.V., and Covas, J.A. (2012) In-line near-infrared spectroscopy for the characterization of dispersion in polymer-clay nanocomposites. Polym. Testing, 31, 527.

73 Cioffi, M., Ganzeveld, K.J., Hoffmann, A.C., and Janssen, L.P.B.M. (2002) Rheokinetics of linear polymerization. A literature review. Polym. Eng. Sci., 42, 2383.

74 Van Puyvelde, P., Velankar, S., and Moldenaers, P. (2001) Rheology and morphology of compatibilized polymer blends. Curr. Opin. Colloid Interface Sci., 6, 457.

75 Cassagnau, P., Gimenez, J., Bounor-Legaré, V., and Michel, A. (2006) New rheological developments for reactive processing of poly( $\varepsilon$-caprolactone). C. R. Chimie, 9, 1351.

76 Grace, G.H. (1982) Dispersion phenomena in high viscosity immiscible fluid systems and application of static mixers as dispersion devices in such systems. Chem. Eng. Commun., 14, 225.

77 Teixeira, P.F., Hilliou, L., Covas, J.A., and Maia, J.M. (2013) Assessing the practical utility of the hole-pressure method for the in-line rheological characterization of polymer melts. Rheol. Acta, 52, 661.

78 Martyn, M.T., Nakason, C., and Coates, P.D. (2000) Measurement of apparent extensional viscosities of polyolefin melts from process contraction flows. J. Non-Newt. Fluid Mech., 92, 203. 
79 Kopplmayr, T., Luger, H.-J., Burzic, I., Battisti, M.G., Perko, L., Friesenbichler, W., and Miethlinger, J. (2016) A novel online rheometer for elongational viscosity measurement of polymer melts. Polym. Testing, 50, 208.

80 Cogswell, F.N. (1972) Converging flow of polymer melts in extrusion dies. Polym. Eng. Sci., 12, 64.

81 Binding, D.M. (1988) An approximate analysis for contraction and converging flows. J. Newt. Fluid Mech., 27, 173.

82 Rauwendaal, C. and Fernandez, F. (1985) Experimental study and analysis of a slit die viscometer. Polym. Eng. Sci., 25, 765.

83 Pabedinskas, A., Cluett, W.R., and Balke, S.T. (1991) Development of an in-line rheometer suitable for reactive extrusion processes. Polym. Eng. Sci., 31, 365.

84 Horvat, M., Azad Emin, M., Hochstein, B., Willenbacher, N., and Schuchmann, H.P. (2013) A multiple-step slit die rheometer for rheological characterization of extruded starch melts. J. Food Eng., 116, 398.

85 Kalyon, D.M., Gokturk, H., and Bozan, I. (1997) Adjustable Gap In-line Rheometer. SPE-ANTEC 1997, 2286.

86 Kalyon, D.M., Gevgilili, H., Kowalczyk, J.E., Prickett, S.E., and Murphy, C.M. (2006) Use of adjustable-gap on-line and off-line slit rheometers for the characterization of the wall slip and shear viscosity behavior of energetic formulations. J. Energetic Mat., 24, 175.

87 Hochstein, B., Kizilbay, Z., Horvat, M., Schuchmann, H.P., and Willenbacher, N. (2015) Innovatives inline-rheometer zur bestimmung des starkeabbaus im extruder. Chem. Ing. Tech., 87, 1.

88 Chiu, S.-H., Yiu, H.-C., and Pong, S.-H. (1997) Development of an in-line viscometer in an extrusion molding process. J. Appl. Polym. Sci., 63, 919.

89 Coates, P.D., Rose, R.M., and Barghash, M.A. (2001) A "Bleed" on Line Rheometer for Polymer Melts. SPE-ANTEC 2001.

90 Kelly, A.L., Woodhead, M., Coates, P.D., Barnwell, D., and Marin, K. (2000) In-process rheometry studies of LDPE compounds. Int Polym. Proc., XV, 355.

91 Donato, N. (2012) A contribution to the on-line extensional characterization of polymer melts. MSc thesis. University of Minho, Portugal.

92 Springer, P., Broadkey, R.S., and Lynn, R.E. (1975) Development of an extrusion rheometer suitable for on-line rheological measurements. Polym. Eng. Sci., 15, 583.

93 Vergnes, B., Della Valle, G., and Tayeb, J. (1993) A specific slit die rheometer for extruded starchy products - design, validation and application to maize starch, Rheol. Acta, 32, 465.

94 Robin, F., Engmann, J., Tomasi, D., Breton, O., Parker, R., Schuchmann, H.P., and Palzer, S. (2010) Adjustable twin-slit rheometer for shearviscosity measurement of extruded complex starchy melts. Chem. Eng. Tech., 33, 1672.

95 Covas, J.A., Carneiro, O.S., Costa, P., Machado, A.V., and Maia, J.M. (2004) On-line monitoring techniques for studying the evolution of physical, 
rheological and chemical effects along the extruder. Plast. Rubber Compos. Macromol. Eng., 33(1), 55.

96 Maia, J.M., Carneiro, O.S., Machado, A.V., and Covas, J.A. (2002) On-line rheometry for twin-screw extrusion (along the extruder) and its applications. Appl. Rheol., 12, 18.

97 Machado, A.V., Maia, J.M., Canevarolo, S.V., and Covas, J.A. (2004) Evolution of peroxide-induced thermomechanical degradation of polypropylene along the extruder. J. Appl. Polym. Sci., 91, 2711.

98 Zschuppe, V., Geilen, T., Maia, J.M., Covas, J.A., and Petri, H.-M. (2006) The piezo axial vibrator - new perspectives for on-line viscosity measurements on polymers. Thermo Electron Corporation, Technical Note LR-57, 2006.

99 Mould, S., Barbas, J.M., Machado, A.V., Nóbrega, J.M., and Covas, J.A. (2011) Measuring the rheological properties of polymer melts with on-line rotational rheometry. Polym. Testing, 30, 602.

100 Mould, S., Barbas, J.M., Machado, A.V., Nóbrega, J.M., and Covas, J.A. (2012) Monitoring the production of polymer nanocomposites by melt compounding with on-line rheometry. Int. Polym. Proc., XXVII, 527. 